\title{
ANÁLISE DA ESTRATÉGIA DE REDUÇÃO DO CONSUMO DE TABACO POR MEIO DA ELEVAÇÃO DOS PREÇOS NO BRASIL SOB A ÓTICA DA TEORIA ECONÔMICA: ESTIMATIVA E IMPLICAÇÕES'
}

\author{
Matheus Lazzari Nicola² \\ Mario Antonio Margarido 3 \\ Pery Francisco Assis Shikida ${ }^{4}$
}

\begin{abstract}
Este artigo coloca em discussão uma estratégia alternativa para a política de controle do consumo de tabaco no Brasil, visto que o consumo de tabaco, há algum tempo, não gera exclusivamente problemas de saúde. 0 objetivo deste texto foi aprofundar o debate sobre a receita tributária gerada a partir da produção de produtos derivados do tabaco para compensar suas externalidades negativas, estimando a curva de Laffer para esse mercado. Os resultados encontrados sugerem que a alíquota ótima para o imposto sobre produtos industrializados (IPI) é de 32,45\%; no entanto, observou-se que a alíquota real do IPI, entre 2012 e 2015, ficou sempre próxima à alíquota ótima estimada. Desse modo, o foco seguinte recaiu sobre a exigência de preço mínimo no varejo para os cigarros no país, simulando o comportamento do mercado em função da eliminação dessa estratégia. Com essa simulação estática-comparativa, verificou-se que o faturamento da indústria de cigarros nacional aumentaria 45,14\% e o total de IPI arrecadado aumentaria 44,86\%. Além disso, no cenário ideal, o ônus do IPI deveria ser redistribuído para que a alíquota real do IPI permaneça próxima à alíquota ótima estimada, viabilizando um produto para indústria nacional capaz de competir com o produto ilegal. Concluiu-se que a eliminação da estratégia de preços mínimos afetaria drasticamente a rentabilidade da indústria ilegal de cigarros, transferiria recursos para o Estado ampliar sua capacidade de amenizar as externalidades negativas geradas pelo consumo de tabaco, bem como transferiria recursos para indústria nacional legal de tabaco, que respeita as normas ambientais, sanitárias e trabalhistas no país.
\end{abstract}

Palavras-chave: curva de Laffer; política de controle de tabaco; mercado ilegal de cigarro.

\section{ANALYSIS OF THE STRATEGY TO REDUCE TOBACCO CONSUMPTION THROUGH RISING PRICES IN BRAZIL UNDER ECONOMIC THEORY VIEW: ESTIMATION AND IMPLICATIONS}

This paper discusses an alternative strategy for a tobacco control policy in Brazil, since tobacco consumption, for some time, does not generate only health problems. The objective of this paper was approved for the debate on a tax revenue generated from the production of tobacco products to compensate for its negative externalities, estimating a Laffer Curve for this market. The results suggest that an optimal IPI rate is $32.45 \%$, however, it has been observed that a real IPI rate between 2012 and 2015 was always close to the estimated optimum aliquot. Thus, focus on the requirement of minimum retail price for cigarettes in the country, simulating the behavior of the

1. DOI: http://dx.doi.org/10.38116/ppp55art10

2. Doutorando do Programa de Teoria Econômica da Universidade de São Paulo (USP).E-mail: <matheus.In@usp.br>.

3. Pesquisador científico nível VI do Instituto de Economia Agrícola (IEA).E-mail: <margaridoma@gmail.com>.

4. Professor associado da Universidade Estadual do Oeste do Paraná (Unioeste) e bolsista de produtividade em pesquisa do Conselho Nacional de Desenvolvimento Científico e Tecnológico (CNPq).E-mail:<peryshikida@hotmail.com>. 
market due to the elimination of the strategy. With this static-comparative simulation, it was found that cigarette industry revenues increased by $45.14 \%$ and the total IPI collected would increase by $44.86 \%$; furthermore, no scenario ideal, the burden of IPI should be redistributed to That the real IPI rate remains close to the estimated optimum rate and enables a product for the domestic industry capable of competing with the illegal product. It was concluded that the elimination of the pricing strategy is drastically affected the profitability of the illegal cigarette industry, transferring resources to the state from its ability to soften as negative externalities generated by cigarette consumption, as well as transferring resources to the national legal industry Respecting environmental, health and labor standards in the country.

Keywords: Laffer curve; tobacco control policy; illegal cigarette market.

\section{ANÁLISIS DE LA ESTRATEGIA PARA REDUCIR EL CONSUMO DE TABACO A TRAVÉS DEL CRECIMIENTO DE LOS PRECIOS EN BRASIL DESDE EL PUNTO DE VISTA DE LA TEORÍA ECONÓMICA: ESTIMACIONES E IMPLICACIONES}

Este artículo analiza una estrategia alternativa para la política de control de consumo del tabaco en Brasil, ya que el consumo de tabaco, por algún tiempo, no genera exclusivamente problemas de salud. El objetivo de este artículo fue profundizar el debate sobre los ingresos fiscales generados por la producción de productos derivados del tabaco para compensar sus externalidades negativas, estimando la curva de Laffer para este mercado. Los resultados encontrados sugieren que la tasa óptima para el IPI es 32.45\%, sin embargo, se observó que la tasa real del IPI entre 2012 y 2015 siempre estuvo cerca de la tasa óptima estimada. Por lo tanto, el siguiente enfoque se centró en el requisito de precio minorista mínimo para los cigarrillos en el país, simulando el comportamiento del mercado debido a la eliminación de esta estrategia. Con esta simulación comparativa estática, se verificó que la facturación de la industria de cigarrillos nacional aumentaría $45.14 \%$ y el IPI total recolectado aumentaría $44.86 \%$, además, en el escenario ideal, la carga del IPI debería redistribuirse para que la tasa de IPI real se mantenga cercana a la tasa óptima estimada y hacer que un producto para la industria nacional sea capaz de competir con el producto ilegal. Se concluyó que la eliminación de la estrategia de precio mínimo afectaría drásticamente la rentabilidad de la industria ilegal de cigarrillos, transferiría recursos al Estado para expandir su capacidad para aliviar las externalidades negativas generadas por el consumo de tabaco, y transferiría recursos a la industria legal nacional del tabaco que respetan los estándares ambientales, de salud y laborales en el país.

Palabras clave: curva de Laffer; política de control de tabaco; mercado ilegal de cigarillos.

\section{ANALYSE DE LA STRATÉGIE DE RÉDUCTION DE LA CONSOMMATION DE TABAC AU BRÉSIL DU POINT DE VUE DE LA THÉORIE ÉCONOMIQUE: ESTIMATION ET IMPLICATION}

Cet article examine une stratégie alternative pour la politique de lutte antitabac au Brésil, car la consommation de tabac, pendant un certain temps, ne génère pas exclusivement des problèmes de santé. Cet article cherche d'approfondir le débat sur les recettes fiscales générées par le marché du tabac pour compenser ses externalités négatives, en estimant la courbe de Laffer pour ce marché. Les résultats trouvés suggèrent que la taxe sur la production industrielle est de $32,45 \%$, mais il a été observé que le taux réel entre 2012 et 2015 était toujours proche du taux optimal estimé. 
L'accent a ensuite été mis sur le prix minimum de vente au détail des cigarettes dans le pays, simulant le comportement du marché en raison de l'élimination de cette stratégie. Avec cette simulation statique et comparative, il a été constaté que le chiffre d'affaires de l'industrie nationale de la cigarette augmenterait de $45,14 \%$ et que le total des taxes collectées augmenterait vers $44,86 \%$. Dans le scénario idéal, la charge de taxe sur les produits industrialisés devrait être redistribuée à que le taux réel reste proche du taux optimal estimé et rend un produit national capable de concurrencer le produit illégal. La recherche a conclu que l'élimination de la stratégie du prix minimum affecterait considérablement la rentabilité de l'industrie illégale de la cigarette, qui transférerait des ressources à l'État pour accroître sa capacité à atténuer les externalités négatives générées par la consommation de tabac, ainsi que des ressources à l'industrie nationale du tabac légale et le respect des normes environnementales, sanitaires et du travail du pays.

Mots-clés: courbe de Laffer; politique de lutte antitabac; marché illégal des cigarettes.

JEL: C13; H30.

\section{INTRODUÇÃO E FORMULAÇÃO DO PROBLEMA}

O guia para implementação do art. 6o da Convenção-Quadro para o Controle do Tabaco (CQCT), da Organização Mundial de Saúde (OMS), sugere aos Estados-membros a adoçáo de políticas tributárias e, quando apropriado, políticas de preços para produtos derivados do tabaco com o objetivo de reduzir o seu consumo como medidas auxiliares para proteger as presentes e futuras geraçóes contra as consequências sanitárias, sociais, ambientais e econômicas derivadas do consumo do tabaco (WHO, 2010).

Paes (2014) deduz que a tributação sobre produtos derivados do tabaco aumenta a receita tributária, cria uma fonte de financiamento para a correçáo das externalidades negativas do tabaco e desestimula o seu consumo. Logo, se a alíquota dos tributos sobre estes é baixa e o governo a eleva, então, aumenta-se a arrecadação, amplia-se sua capacidade de corrigir as externalidades e o consumo reduz-se. No entanto, progressivos aumentos dessas alíquotas levarão a receita tributária a um ponto estacionário que, a partir dele, se as alíquotas continuarem subindo, a receita tributária reduzirá tendendo assintoticamente a zero, a medida que o número de consumidores dispostos a pagar um preço maior também tende assintoticamente a zero.

Outra possibilidade, seria a simples proibição da produção, distribuição e comercialização dos produtos derivados do tabaco, no entanto, essa possibilidade criaria um mercado ilegal, consequência idêntica à elevação do seu preço muito acima do ponto de estacionariedade da receita tributária, e traria consigo todas as dificuldades inerentes ao combate de drogas ilícitas e, ainda, exigiria recursos de outras fontes para sustentar as açôes para sua coação. Nessa lógica, o objetivo das políticas públicas, para atender os anseios de WHO (2003) de proteger as presentes e futuras geraçóes contra as consequências do consumo do tabaco, deve 
ser o equilíbrio entre a receita tributária com origem sobre o consumo de produtos derivados do tabaco e a necessidade de financiamento de açóes que compensem as suas externalidades negativas.

Resultados empíricos desse desequilíbrio, com a irrevogável consequência da expansão do mercado ilegal de tabaco, foram discutidos por Gardes e Merrigan (2014) no dilema do Canadá de reduzir ou não as alíquotas dos tributos sobre produtos derivados do tabaco para coibir o crescimento desse mercado ilegal. Na primavera de 1994, cinco províncias canadenses adotaram essa estratégia e, nos anos subsequentes, erradicaram o contrabando. No entanto, com os dados disponíveis, os autores conseguiram observar que, com a consequente redução do preço, entre os fumantes adultos, a elasticidade-preço da demanda por produtos derivados do tabaco passou de -0,2 para - 0,4 e, entre os jovens fumantes, a elasticidade passou de -0,4 para -0,7. Esse aumento do consumo forçou o governo dessas províncias a aumentarem, gradativamente, a alíquota dos tributos para desistimulá-lo, ação essa que culminou no retorno do contrabando. Os autores concluíram que o esforço brusco para erradicar o contrabando, em 1994, aumentou em $5 \%$ a proporção de jovens fumantes e, ainda, alertaram que, se essa estratégia for novamente adotada, estimularia a emerção de uma nova geração de fumantes.

Na mesma direção, Chaloupka, Yurekli e Fong (2012) analisaram a estrutura tributária arquitetada por 182 países para controlar o consumo de tabaco e concluíram que, por um lado, países com regras tributárias complexas apresentaram dificuldades tanto para gerar receitas quanto para controlar o consumo de tabaco, pois regras tributárias complexas são difíceis de administrar e ampliam as possibilidades de sonegação e evasão fiscal. Por outro lado, em países com estruturas tributárias simples, os autores observaram eficiência tanto para gerar receitas por meio de tributos quanto para controlar o consumo. Além disso, o estudo revelou que apenas 38 desses países destinavam a receita tributária com origem sobre o consumo de produtos derivados do tabaco para açóes de controle do tabaco e promoção da saúde pública. Os demais países utilizavam a receita para financiar outros gastos com o sistema público de saúde e, alguns desses países, para financiar outros gastos em outras áreas de interesse do governo, desvio este que corrompe o objetivo de amenizar as externalidades negativas derivadas do consumo do tabaco, objetivo fim das políticas de controle do tabaco.

Nesse sentido, a discussão sobre como as políticas públicas devem ser arquitetadas para equilibrar o consumo de tabaco e suas externalidades negativas deve, obrigatoriamente, iniciar pela análise da elasticidade-preço da demanda por produtos derivados do tabaco. Essa análise é essencial para identificar sobre quem recairá o ônus da tributação, para mensurar a variação da demanda após a variação de preço induzida pela alteração das alíquotas dos tributos, bem como para 
avaliar a eficiência de políticas públicas com o objetivo de modificar o padrão de comportamento desses consumidores e, por consequência, avaliar se essas açóes estão realmente compensando externalidades negativas do consumo de tabaco.

Logo, de acordo com a teoria microeconômica, países com elasticidade-preço da demanda para produtos derivados do tabaco abaixo de um, apresentam demanda resistente em relação ao aumento do preço com tendências à inelasticidade e, portanto, teriam margem para continuar a aumentar a alíquota dos tributos que incidem sobre o consumo desses produtos até seu ponto de estacionariedade da receita tributária. Nessa tendência, o ônus da elevação da alíquota tributária recairá sobre os consumidores, pois as empresas conseguirão repassar o novo aumento de tributo por meio dos preços sem afetar significativamente sua demanda.

No Brasil, Carvalho e Lobão (1998) estimaram a elasticidade-preço da demanda por cigarros legais, utilizando uma série temporal bimestral entre 1983 e 1994. Os coeficientes encontrados foram - 0,14 , para o curto prazo, e $-0,49$, para o longo prazo. Iglesias et al. (2007) realizaram a mesma estimativa, mas utilizando uma série temporal bimestral entre 1991 e 2005, e os coeficientes encontrados foram $-0,27$, para o curto prazo, e $-0,48$, para o longo prazo. Esses resultados corroboram com a estratégia de elevação de preço, por meio da tributação, para desestimular a demanda e reduzir as externalidades negativas relativas ao uso de tabaco.

Levy, Almeida e Szklo (2012) estruturaram um modelo para avaliar a eficiência da política de controle de tabaco brasileira. As estimativas encontradas indicam que houve uma redução de quase 50\% no número de fumantes, entre 1989 e 2010 , e que $46 \%$ dessa redução foi motivada pela estratégia de elevação do preço do tabaco por meio da tributaçấo. Por sua vez, Iglesias et al. (2017) calcularam a proporçấo do consumo de tabaco de origem ilícita e inferiram o resultado para todo o território brasileiro, observando que a proporção do mercado ilegal aumentou de $16,6 \%$, em 2008 , para $31,1 \%$, em 2013 , evidenciando que os fumantes estão encontrando alternativas à estratégia de controle do tabaco vigente. Ressalta-se ainda o cuidado dos autores em retirar da rotina de cálculo os consumidores que se classificaram como "fumantes ocasionais". Outro resultado relevante desse estudo é que a diferença de preço entre o cigarro lícito e o ilícito aumentou de $-53,0 \%$, em 2008, para -58,4\%, em 2013.

Conforme observado, a política de controle do tabaco brasileira realmente obteve êxito em seu objetivo de reduzir o número de consumidores de tabaco em relação à população. Entretanto, essa estratégia começa a mostrar sinais de exaustão, visto que, de acordo com Pesquisa Especial de Tabagismo (PETab), realizada por IBGE (2008) - sendo esta a principal base de dados sobre o tema no Brasil -, 93,0\% dos entrevistados que se classificaram como "consumidores frequentes de tabaco" acreditavam que fumar poderia causar graves doenças, mas destes, 
$81,4 \%$ não estavam pensando em parar de fumar antes dos próximos doze meses. Essa evidência indica que, caso a estratégia de aumentar o preço para reduzir o consumo de tabaco continue, chegar-se-á a um ponto em que o seu resultado será apenas a transferência de renda desses consumidores para o Estado e não mais contribuirá para a reduçấo da demanda.

Outro indicativo que corrobora com a exaustáo da política de controle do tabaco é sua capacidade de compensar as externalidades negativas geradas pelo seu consumo. Pinto e Pichon-Riviere (2012) estruturaram um modelo de microssimulação probabilístico para estimar o impacto das enfermidades relacionadas ao consumo de tabaco no sistema de saúde brasileiro. Suas estimativas aproximam-se de $\mathrm{R} \$ 23,37$ bilhóes ao ano (a.a.) em 2011, aproximadamente 28,89\% (R \$ 80,87 bilhóes) do orçamento do Ministério da Saúde (MS) no mesmo ano (FGV, 2015). Por seu turno, a receita tributária total dos produtos derivados do tabaco no Brasil em 2011 foi de, aproximadamente, R \$ 6,77 bilhóes, 71,03\% menor do que o necessário para compensar os gastos com saúde (IBGE, 2011). Poder-se-ia também considerar o gasto que o governo tem com o sistema jurídico e com a estrutura de combate ao contrabando de produtos derivados do tabaco, mas não foram encontrados estudos com metodologias sólidas sobre este tema.

Desse modo, com base nessas evidências, questiona-se se a política de controle de tabaco brasileira adotada continua sendo uma estratégia eficiente para reduzir as externalidades negativas criadas pelo consumo do tabaco. Questiona-se também se os objetivos propostos pela OMS são ingênuos ao ponto de não levarem em consideração a consciência do indivíduo sobre os malefícios do consumo do tabaco e seu direito ao ato de fumar. Além disso, percebe-se que o atual esforço de combater o contrabando de produtos derivados do tabaco beneficia a indústria de tabaco e transfere para a sociedade esse ônus.

Diante desses questionamentos, o objetivo geral deste artigo é aprofundar o debate sobre a estratégia de reduzir o consumo de tabaco por meio da elevação de preços, tendo como parâmetro para essa discussão a receita tributária gerada a partir do imposto sobre produtos industrializados (IPI), que incide sobre a produção de produtos derivados do tabaco para compensar suas externalidades negativas. Para alcançar esse objetivo, pretende-se: i) estimar a curva de Laffer para verificar qual seria a alíquota que maximizaria a arrecadação por meio do IPI; ii) analisar o efeito da estratégia de preço mínimo explícita na legislação brasileira para o mercado de tabaco; bem como iii) calcular o quanto a arrecadação aumentaria, em um cenário ideal, para auferir a nova capacidade do Estado em compensar as externalidades negativas geradas pelo consumo de tabaco.

Portanto, este estudo justifica-se por ampliar o contraditório sobre o tema, visto que a maioria dos trabalhos revisados consideraram que a política de controle 
de tabaco brasileira foi bem-sucedida nos últimos anos e há poucos estudos sobre o impacto dessa estratégia além da redução do número de consumidores de tabaco. Para isso, este artigo foi estruturado em quatro seçóes, além desta breve introdução e formulação do problema. $\mathrm{Na}$ seção 2 , encontra-se a revisão de literatura sobre metodologias utilizadas para estimar a curva de Laffer. Na seção 3, apresenta-se a base de dados utilizada e a metodologia adotada neste artigo. $\mathrm{Na}$ seção 4, são apresentados os resultados obtidos; e, por fim, são expostas as considerações finais.

\section{PRINCIPAIS ASPECTOS DA CURVA DE LAFFER ${ }^{5}$}

Para discutir a receita tributária advinda dos produtos derivados do tabaco, utilizar-se-á a curva de Laffer, a qual mostra a relação entre a alíquota de imposto incidente sobre determinado produto e sua respectiva arrecadação gerada para o Estado. É necessário enfatizar que esta relação gera dois efeitos: substituição e renda.

Em linhas gerais, o efeito substituição representa a troca das decisões dos agentes econômicos como resultado nas alteraçôes das alíquotas dos impostos dos produtos, ou seja, uma elevação das alíquotas de imposto sobre determinado produto torna este produto mais caro, desestimulando seu consumo, pois há perda de poder de compra por parte do consumidor e, consequentemente, aumenta o consumo de produtos substitutos. Em termos microeconômicos, o efeito substituição representa o deslocamento sobre determinada curva de indiferença, reduzindo a quantidade demandada de um produto; mas, por sua vez, aumenta o consumo de outro produto, porém, mantendo constante o nível de bem-estar do consumidor.

O segundo estágio relativo a este ajustamento no preço é denominado de efeito renda, neste caso, ocorre troca da capacidade aquisitiva dos consumidores. Mantidos os preços dos produtos constantes, um dado aumento de renda para o consumidor possibilita que sua restrição orçamentária consiga atingir uma curva de indiferença mais elevada, aumentando o bem-estar do consumidor. Em outras palavras, o efeito renda permite que o consumidor se movimente entre as curvas de indiferença, proporcionando-lhe um aumento ou redução de bem-estar. ${ }^{6}$

Sob o ponto de vista do governo, há necessidade de cobrança de impostos para financiar os gastos com saúde, educação, segurança etc. Assim, o governo precisa fixar alíquotas de impostos. No entanto, o governo deve calibrar com máxima precisão quais são as alíquotas que geram a maior arrecadação possível, pois, alíquotas muito elevadas incentivam maior evasão de impostos, enquanto alíquotas muito baixas impossibilitam que o governo obtenha recursos necessários para cumprir com suas funçóes diante da sociedade.

5. Esta seção baseia-se fundamentalmente em Laffer (2004) e Trabandt e Uhlig (2011).

6. Detalhes sobre os efeitos substituição e renda podem ser encontrados em Varian (1996). 
No âmbito macroeconômico, a elevação de tributos reduz a renda disponível e interfere nos preços relativos dos produtos produzidos internamente, com impactos diversos sobre os componentes da demanda agregada, afetando negativamente o produto da economia.7 Por isso, é de extrema relevância determinar qual é a alíquota ótima de imposto, que incidirá sobre cada produto e, ainda, levar em consideração as particularidades de cada mercado.

\subsection{A matemática da curva de Laffer}

Para se determinar qual deve ser a alíquota ótima, utiliza-se a curva de Laffer. Matematicamente, esta curva é representada como:

$$
I T R_{t}=f\left(T_{t}^{2}, T_{t}\right),
$$

em que $I T R_{t}$ corresponde à arrecadação tributária real per capita no período $t$; e $T_{t}$ representa a arrecadação tributária como percentual do produto interno bruto (PIB).

Em função da presença do termo quadrático na equação (1), a curva de Laffer tem o formato de uma parábola côncava.

O gráfico 1 apresenta o comportamento da curva da equação (1). No eixo horizontal, está o percentual da alíquota do imposto; no eixo vertical, se encontra a receita obtida pelo governo em função da alíquota estabelecida pelo próprio governo. Por se tratar de uma função matemática, a questão reside em maximizar esta função. Portanto, é necessário derivar esta função e igualar a zero para se encontrar o ponto de máximo. Basicamente, dado que a alíquota do imposto é um percentual cobrado sobre o preço do produto, três são os pontos mais relevantes da curva de Laffer. Quando a alíquota é igual a zero, a arrecadação do governo é igual a zero (a). No outro extremo, quando a alíquota é igual a 100\%, a arrecadação do governo também é nula (c), pois nenhuma unidade de produto é vendida dada a magnitude do imposto cobrado e/ou há evasão fiscal. O terceiro ponto relevante consiste no ponto de máximo da função e, neste caso, inclinação da reta é igual a zero (b), ou seja, paralela ao eixo horizontal do gráfico 1.

7. Discussão a respeito do impacto do tributo sobre o produto da economia ver em: Simonsen e Cysne (2007). 
GRÁFICO 1

\section{Curva de Laffer}

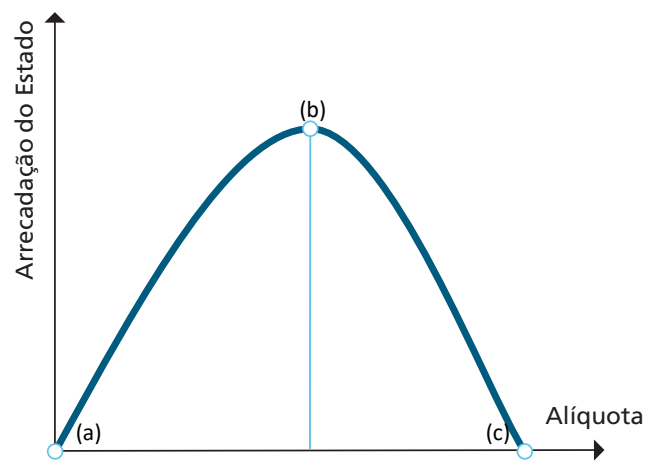

Fonte: Laffer (2004).

\subsection{Modelo econométrico da curva de Laffer}

Econometricamente, a curva de Laffer é representada pela seguinte fórmula:

$$
I T R_{t}=\beta_{1} T_{t}+\beta_{2} T_{t}^{2}+\beta_{3} t+\varepsilon_{t},
$$

em que $t$ corresponde a uma tendência determinística e representa os resíduos da regressão, os quais, por hipótese, devem ser identicamente e independentemente distribuídos (iid), ou seja, não podem apresentar autocorrelação.

\subsection{Definição das variáveis na curva de Laffer}

A variável arrecadação tributária real per capita $(I T R)$ é definida como:

$$
I T R_{t}=\frac{\frac{I T N_{t}}{I P C A_{\text {base }}}}{P_{t}} .
$$

Em que $I T N_{t}$ corresponde à arrecadação tributária nominal (preços correntes) no período $t, I P C A_{\text {base }}$ é o Índice Nacional de Preços ao Consumidor Amplo (IPCA), o qual é o indicador da inflaçáo oficial no Brasil para o período base; e $P_{t}$ é a população do Brasil no período $t$. A relação entre arrecadação tributária nominal e PIB nominal, ambos no tempo $t$, é representada como.

$$
T_{t}=\frac{I T N_{t}}{\text { PIB Nominal }} \text {. }
$$

Logo, para cumprir o objetivo deste artigo, se utilizou o mesmo modelo, porém adaptando as variáveis do modelo para a indústria de tabaco brasileira, em que $I T N_{t}$ corresponde à arrecadação nominal de IPI sobre produtos derivados do 
tabaco no período $t$, bem como $P_{t}$ é a população de fumantes no Brasil no período $t$. Além disso, a alíquota efetivamente paga pela indústria de tabaco brasileira no

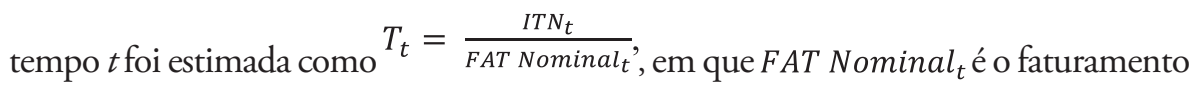
nominal da referida indústria no período $t$.

Espera-se que os parâmetros da regressão sejam estatisticamente significativos, sendo que $\beta_{1}$ seja positivo e $\beta_{2}$ seja negativo, para garantir que a curva tenha o formato de $\mathrm{U}$ invertido. Após obter as estimativas dos parâmetros, deve-se igualar a equação a zero para se obter a seguinte relação: $\frac{-\beta_{1}}{2 \beta_{2}}$.

\section{BASE DE DADOS E MÉTODOS}

A série da "arrecadação nominal de cigarro no Brasil" levou em consideração somente a incidência do IPI, obtida no próprio site da Receita Federal do Brasil (RFB), para compor a variável $I T N_{t}$. No mesmo site, há também a série denominada "outros impostos e contribuiçôes", no entanto, essa série agrega o valor arrecadado pelo Programa de Integração Social (PIS), pelo Programa de Formação do Patrimônio do Servidor Público (Pasep) e pela Contribuição para o Financiamento da Seguridade Social (Cofins), informação não utilizada nas estimativas. No mesmo endereço eletrônico, é possível obter as informaçôes relativas à produção de tabaco no Brasil.

As séries temporais relativas à população do Brasil e ao IPCA foram obtidas no site do Instituto Brasileiro de Geografia e Estatística (IBGE). A série do PIB do Brasil nominal foi extraída do site do Ipeadata. A série mensal relativa ao faturamento da indústria de tabaco no Brasil foi solicitada ao Instituto de Desenvolvimento Econômico e Social de Fronteiras (Idesf).

As séries organizadas têm periodicidade mensal e o período analisado inicia-se em janeiro de 2010 e estende-se até dezembro de 2015, contendo um total de 72 observaçóes. Para obter os respectivos valores corrigidos monetariamente, as séries de arrecadação nominal e do PIB nominal foram deflacionadas pelo IPCA, a preços constantes de dezembro de 2015.

Para construir a série mensal para a população de fumantes no Brasil, $P_{t}$ utilizou-se como proxy a série "população do estado de São Paulo", obtida no site da Fundação Sistema Estadual de Análise de Dados (Seade) para o período de janeiro de 2010 a dezembro de 2015 . No entanto, essa série mensal estava disponível somente a partir de janeiro de 2012. Assim, foi necessário estimá-la para o período de janeiro de 2010 até dezembro de 2011.

Inicialmente, foi calculada a relação percentual mensal da população do estado de São Paulo em relação à população do Brasil (para o período de janeiro de 2012 até dezembro de 2015). Na sequência, foi calculada a relação média para 
o referido período. Posteriormente, dividiu-se a população do estado de São Paulo pelo percentual médio calculado para o período de janeiro de 2012 a dezembro de 2015, e este resultado foi multiplicado por cem. O resultado é uma estimativa da população do Brasil para o período de janeiro de 2010 até dezembro de 2011. Com a série mensal da população brasileira estimada, se utilizou a proporção de fumantes apurados pela Pesquisa Nacional de Saúde (PNS) de 2013, realizada por IBGE (2014), para construir a série mensal para a população de fumantes no Brasil, $P_{t}$.

\subsection{Procedimentos metodológicos}

Com base na teoria da curva de Laffer, foram elaboradas três séries compostas, todas desenvolvidas a partir da arrecadaçáo de IPI sobre produtos derivados do tabaco: i) relação arrecadação real sobre população; ii) relação arrecadação nominal sobre PIB nominal; e iii) arrecadação nominal sobre PIB nominal elevada ao quadrado, para captar a tendência quadrática. Finalmente, cada série foi transformada em índice, cuja base é janeiro de 2010 igual a cem.

Basicamente, uma série de tempo pode ser desagregada em quatro componentes: ciclo, tendência, sazonalidade e componente aleatório. Matematicamente, uma série de tempo pode ser multiplicativa (4) ou aditiva (5), conforme apresentada, respectivamente, por:

$$
\begin{aligned}
& \widehat{Y} m_{t}=\widehat{T}_{t} * \widehat{S}_{t} * \widehat{C}_{t} * \widehat{I}_{t} \\
& \widehat{Y} a_{t}=\widehat{T}_{t}+\widehat{S}_{t}+\widehat{C}_{t}+\widehat{I}_{t},
\end{aligned}
$$

em que $\widehat{Y} m_{t}$ é a série de tempo classificada como multiplicativa; $\widehat{Y} a_{t}$ é a série de tempo classificada como aditiva; $T$, tendência; $S$, sazonalidade; $C$, ciclo; e $I$, componente aleatório, também denominado de componente irregular.

De acordo com Fredo e Margarido (2008, p. 372), a "tendência capta elementos de longo prazo relacionados com a série de tempo, com característica determinística, ou seja, pode ser uma função matemática, ou então estocástica, resultado de um processo aleatório". Neste caso, a tendência estocástica, em economia, mostra alteraçóes no nível da série de tempo, as quais podem ser resultados de mudanças sociais, tecnológicas, condiçóes de mercado, meio ambiente, entre outros.

O componente sazonal capta os padróes regulares da série de tempo, por exemplo: mudanças de temperatura, índice pluviométrico, safra ou entressafra de produtos agropecuários, vendas da indústria, vendas do varejo, entre outros.

Os ciclos são caracterizados por longas ondas, regulares, em torno de uma linha de tendência. $\mathrm{O}$ interesse pelos ciclos está relacionado com seus pontos de mudanças, também denominados de pontos de inflexão, duração, frequência, entre 
outros, conforme Yaffee e McGee (2000). No cálculo do coeficiente de amplitude sazonal (CA) de cada série, foi utilizado o trabalho de Freitas, Ferreira e Barbosa (1998). Este coeficiente tem como base a seguinte fórmula:

$$
C A \%=\frac{(\text { İ́ndice Máximo-Índice Mínimo })}{(\text { Índice Máximo+Índice Mínimo })} * 2 * 100 \text {. }
$$

Para a determinação da ordem de integração de cada variável, foi utilizado o teste de raiz unitária Dickey-Fuller Aumentado (ADF), conforme apresentado em Dickey e Fuller (1979; 1981). No entanto, antes da realização do teste de raiz unitária, é necessário determinar o número de defasagens a serem utilizadas em cada fase do teste de raiz unitária. A correta determinação do número de defasagens é de suma importância, conquanto seja relevante garantir que os resíduos das autorregressóes dos testes de raiz unitárias sejam não correlacionados, de forma a garantir resultados não viesados dos respectivos testes. Para a determinação do número de defasagens, foi utilizado o critério de informação de Akaike Corrigido (AICC). Esse critério, conforme Hurvich e Tsai (1989), é definido como:

$$
\text { AICC }=\log (|\Sigma|)+\frac{2 r}{(T-r / K)},
$$

em que $r$ corresponde ao número de parâmetros estimados; $\Sigma$ denota a estimativa de máxima verossimilhança da matriz de variância-covariância $(\Sigma)$; e K representa a dimensão da série temporal. O AICC (7) se caracteriza por ser assintoticamente eficiente tanto para os modelos de regressão quanto para o caso de modelos de séries temporais. Além disso, o AICC tem melhores propriedades estatísticas do que o critério de informação de Akaike (AIC).

Visando identificar a possível relação de longo prazo entre as variáveis, foi utilizado o teste de cointegraçáo desenvolvido por Engle e Granger (1991). Basicamente, este teste é conduzido em duas etapas. Primeiramente, dado que as variáveis envolvidas apresentem a mesma ordem de integração, deve-se estimar uma equação de regressão com as variáveis em nível, conforme apresentado na equação (8). Esta equação também é denominada de equação de cointegração:

$$
y_{t}=\beta_{1}+\beta_{2} x_{t}+u_{t},
$$

em que $\beta_{1}$ corresponde ao intercepto da regressão e $u_{t}$ são os resíduos da regressão.

$\mathrm{Na}$ verdade, a equação de cointegração apresentada nada mais é do que a equação de regressão tradicional com as variáveis em nível. Uma vez estimada, esta regressão com as variáveis em nível, haja vista que ambas as variáveis são integradas de ordem 1 , o próximo passo consiste em "capturar" os resíduos $\left(u_{t}\right)$ da equação de cointegração, para posteriormente testar se os resíduos são estacionários $I(0)$ ou 
não são estacionários, isto é $I(1)$. Os valores críticos para os testes de raiz unitária sobre os resíduos da equação de cointegração são encontrados em Engle e Granger (1991), Phillips e Ouliaris (1990) e Mackinnon (1991).

Sendo assim, posto que o teste de cointegração envolve a realização de teste de raiz unitária do tipo $\mathrm{ADF}$ sobre os resíduos da equação de cointegração, este teste deve ser efetuado sobre a seguinte equação de resíduos:

$$
\nabla u_{t}=\rho u_{t-1}+\sum_{i=1}^{p} \gamma_{i} \nabla u_{t-1}+e_{t} .
$$

Nesse caso, o termo $\nabla u_{t}$ representa a primeira diferença da variável $u_{t}$, enquanto $\nabla u_{t-1}$ é a primeira diferença defasada da variável $u_{t}$, sendo que o número total de defasagens corresponde a $i$ períodos. Quando o termo $\gamma_{i}$ é igual a zero para todos os is, ao invés do teste ADF, tem-se o teste Dickey-Fuller (DF).

Tendo como base os resíduos da equação de cointegração, o procedimento de verificaçáo da presença ou náo de raiz unitária testa a hipótese nula de que os resíduos têm raiz unitária $(\rho=0)$ contra a hipótese alternativa de que os resíduos são estacionários $(\rho \neq 0)$, ou seja, testa a hipótese nula de que não há cointegração versus a hipótese alternativa de que existe cointegração entre as variáveis $y_{t}$ e $x_{t}$.

Detectada a relação de cointegração entre as variáveis, o próximo passo consiste na inclusão do modelo de correção de erro. Engle e Granger (1991) mostraram que se $y_{t}$ e $x_{t}$ são ambas integradas de ordem um $(I(1))$ e são também cointegradas, entấo existe uma representação de modelo de correção de erro da seguinte forma:

$$
\nabla y_{t}=\omega_{0}+\omega_{1} \nabla x_{t}-\gamma\left(y_{t-1}-\alpha x_{t-1}\right)+\varepsilon_{t},
$$

em que $\nabla y_{t}$ e $\nabla x_{t}$ representam as variáveis $y_{t}$ e $x_{t}$ diferenciadas, respectivamente. Dado que representam as diferenças das variáveis, estes dois elementos captam os efeitos de curto prazo do modelo de correção de erro. O parâmetro $\gamma$ mostra a velocidade pela qual os desvios em relação à condição de equilíbrio são corrigidos em cada período de tempo e também é denominado de termo de correçáo de erro. Portanto, quanto maior o valor estimado de $\gamma$, mais rapidamente os desvios são corrigidos. Ao contrário, quanto menor o seu valor, mais tempo leva para o sistema voltar a uma nova posição de equilíbrio. Finalmente, o termo $\left(y_{t-1}-\alpha x_{t-1}\right)$ representa os resíduos da equação de cointegração, porém, defasados de um período. Vale lembrar que $z_{t}=y_{t}+\alpha x_{t}$, ou seja, $z_{t}$ corresponde aos resíduos da equação de cointegração. Defasando-se esta equação em um período tem-se $z_{t-1}=y_{t-1}+\alpha x_{t-1}$, sendo que o lado direito dessa última expressão corresponde aos resíduos defasados de um período, conforme apresentado na equação de cointegração. 
Por fim, após as correções necessárias nas séries utilizadas para a estimação do modelo, a alíquota ótima estimada para o IPI será calculada após igualar a equação de regressão a zero e derivá-la em relação à arrecadação sobre o PIB, obtendo-se a seguinte equação:

$$
\widehat{\operatorname{Alq}}_{I P I}=\frac{-\beta_{1}}{2 \cdot \beta_{2}} \cdot 100
$$

em que $\widehat{A l q}_{I P I}$ é a alíquota ótima estimada para o IPI; e $\beta_{1}$ e $\beta_{2}$ correspondem ao intercepto e ao coeficiente angular da regressão da curva de Laffer, respectivamente.

\section{RESULTADOS E DISCUSSÃO}

A inspeção visual mostrou que todas as séries apresentam sazonalidade. Em função desta constatação, foi necessário dessazonalizá-las. O processo utilizado para dessazonalizar cada série foi o Método X12 do Bureau of the Census. Assim, foram estimados os respectivos índices sazonais médios para cada variável. O gráfico 2 apresenta a evolução temporal da série original da arrecadação sobre população (D11 - linha azul) e a mesma série dessazonalizada (A1 - linha pontilhada).

\section{GRÁFICO 2}

Relação entre arrecadação do segmento de cigarros e população fumante, original e dessazonalizada - Brasil (jan./dez. 2010-2015)

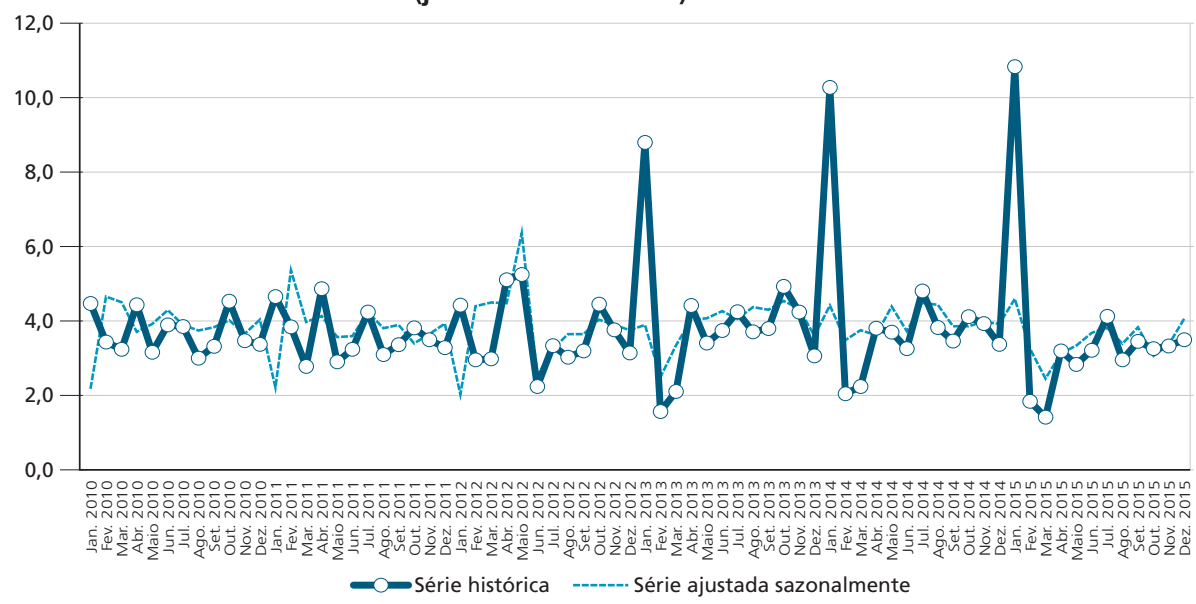

Fontes: Dados básicos da RFB, do IBGE e da Seade.

Elaboração dos autores. 
GRÁFICO 3

Índices sazonais médios mensais da razão entre arrecadação do setor de cigarros e população fumante - Brasil

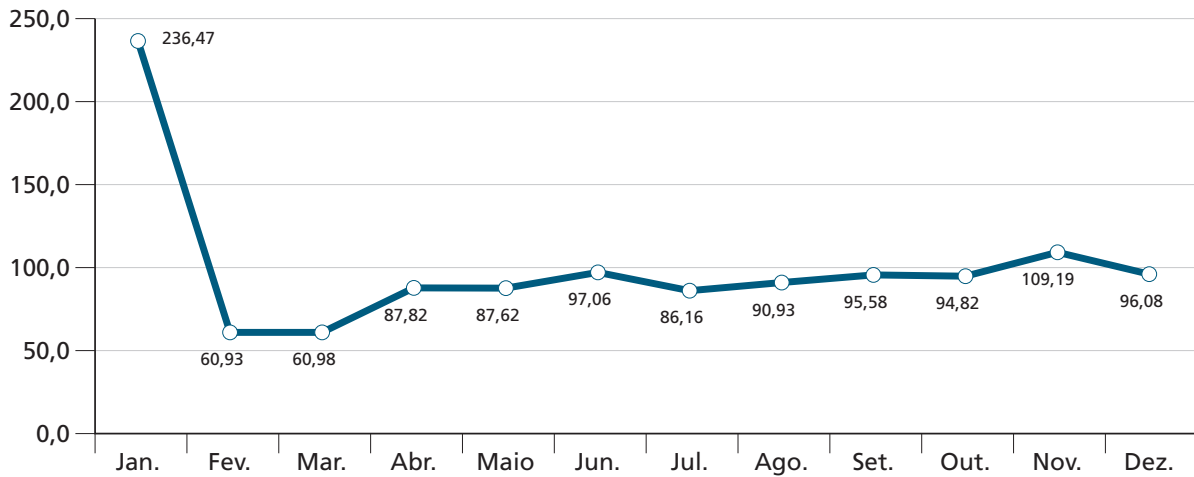

Fontes: Dados básicos da RFB, do IBGE e da Seade.

Elaboração dos autores.

Obs.: Índices sazonais referentes ao período de 2010 a 2015.

O gráfico 3 apresenta os índices sazonais médios mensais da relação arrecadação sobre população. Observa-se que o maior valor para o índice sazonal médio ocorre no mês de janeiro $(236,47)$, enquanto o menor valor se localiza no mês de fevereiro $(60,93)$. O CA sazonal é igual a $118,04 \%$, reforçando a presença de intensa sazonalidade da série. No gráfico 4 , é apresentada a evolução temporal da variável relação da arrecadação e do PIB, tanto em termos da variável original (D11 - linha azul) quanto dessazonalizada (A1 - linha pontilhada).

GRÁFICO 4

Razão entre arrecadação do segmento de cigarros e PIB - Brasil (2010-2015)

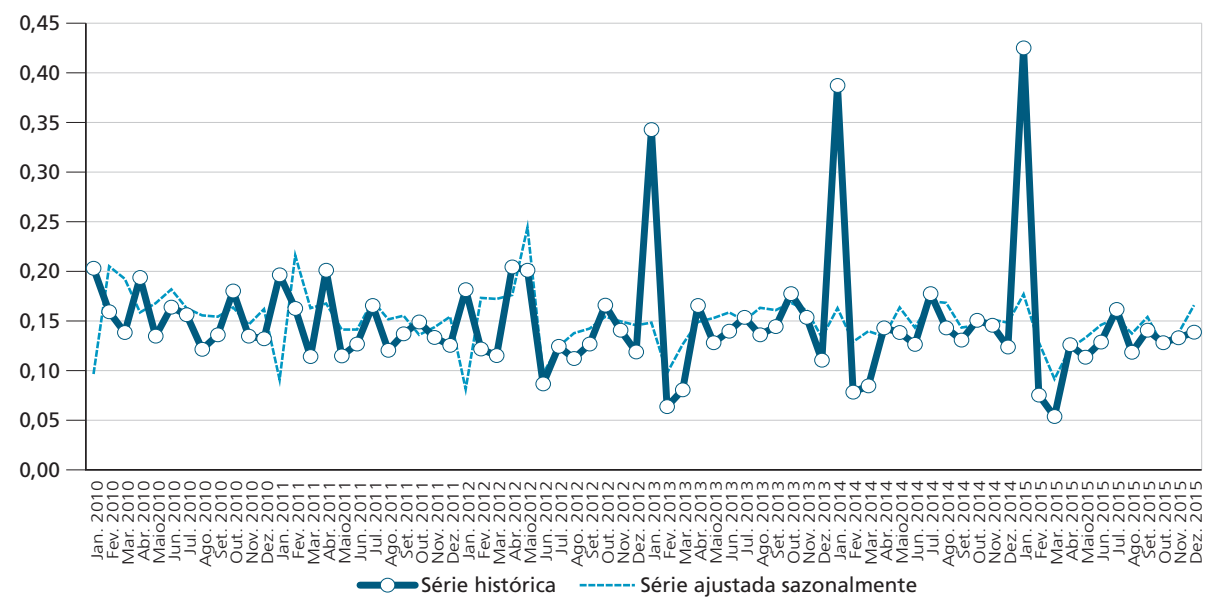

Fontes: Dados básicos da FFB, do Idesf e do Ipeadata.

Elaboração dos autores. 
A forte sazonalidade da arrecadação de IPI sobre produtos derivados do tabaco observada no mês de janeiro pode ser justificada pelo pico de produção que ocorre nos meses de outubro e novembro de cada ano, período de colheita da folha de fumo. A sazonalidade também está associada ao padrão de consumo do tabaco e à política de reajuste de preços mínimos da RFB. $\mathrm{O}$ órgão reajusta os preços mínimos que devem ser praticados pelos varejistas normalmente em janeiro de cada ano, com isso varejistas antecipam suas compras para aproveitar os preços mais baixos do ano anterior. Além disso, os meses de pico de consumo de cigarro coincidem com os meses de pico de consumo de bebidas alcóolicas por ocasião das festividades e confraternizaçóes de fim de ano.

GRÁFICO 5

Índices sazonais médios mensais da razão entre arrecadação do setor de cigarros e PIB - Brasil (2010-2015)

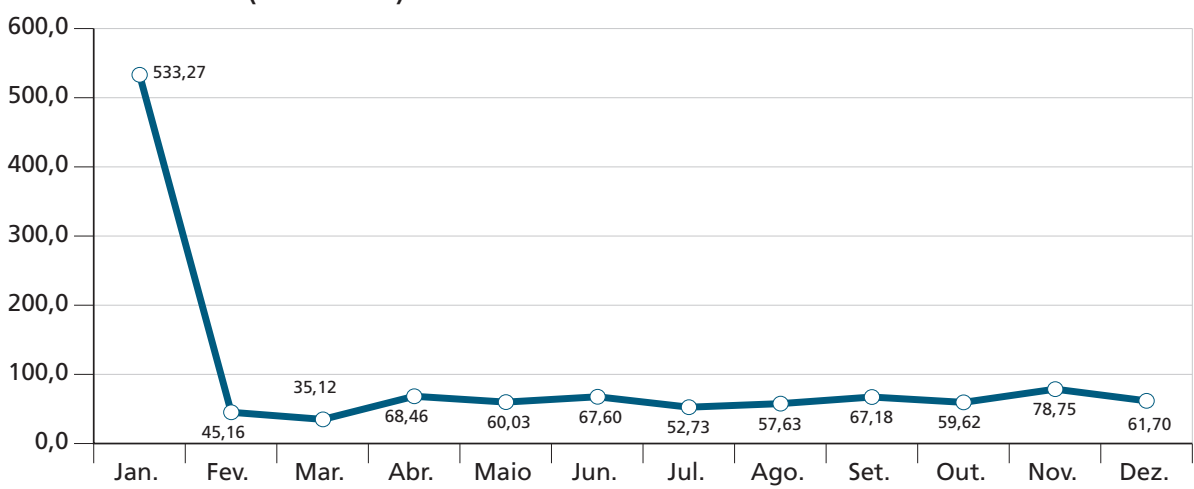

Fontes: Dados básicos da RFB, do Idesf e do Ipeadata.

Elaboração dos autores.

Obs.: Índices sazonais referentes ao período de 2010 a 2015.

Os índices sazonais médios mensais para a variável relação arrecadação e PIB mostram que seu valor máximo ocorre em janeiro $(238,42 \%)$ e o mínimo em março com magnitude igual a 62,22\% (gráfico 5). Esta série apresenta CA sazonal igual a $117,22 \%$, reforçando a presença de sazonalidade nela. O gráfico 6 apresenta o comportamento ao longo do tempo da série relação arrecadação e PIB elevado ao quadrado para a série original (D11 - linha azul) e dessazonalizada (A1 - linha pontilhada). 
GRÁFICO 6

Razão entre arrecadação do segmento de cigarros e PIB, ao quadrado - Brasil (2010-2015)

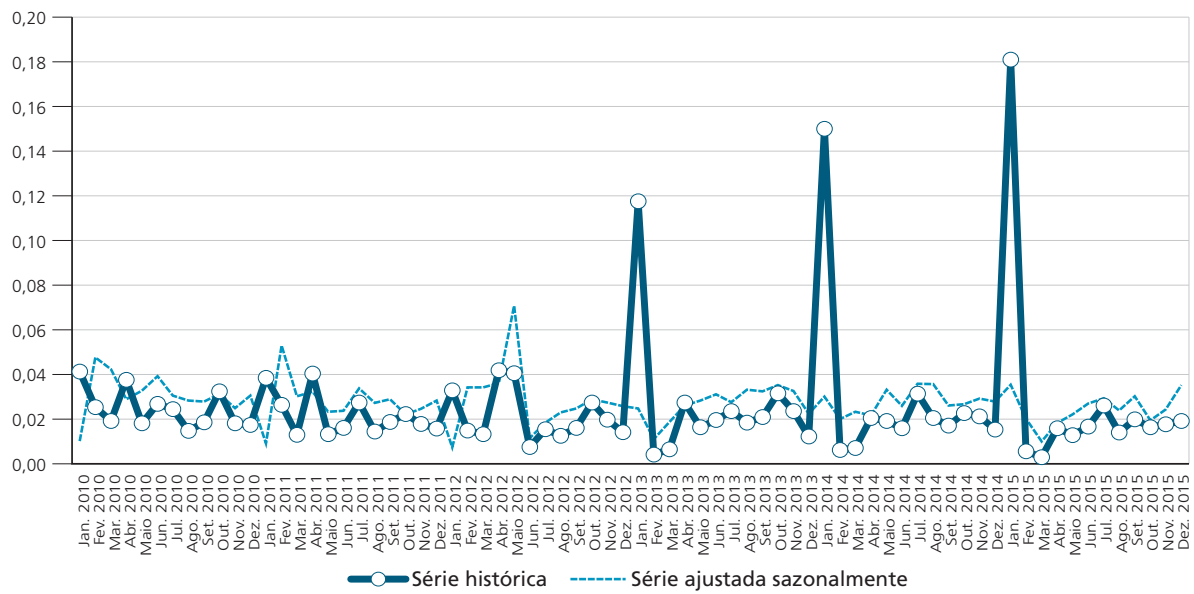

Fontes: Dados básicos da RFB, do Idesf e do Ipeadata.

Elaboração dos autores.

Quanto ao comportamento dos índices sazonais médios mensais, observa-se que a relação arrecadação e PIB ao quadrado apresenta seu valor máximo em janeiro $(533,27 \%)$ e menor valor em março $(35,12 \%)$, conforme apresentado no gráfico 7. O seu CA sazonal é igual a 175,28\%, indicando que a sazonalidade desta série é muito expressiva.

\section{GRÁFICO 7}

Índices sazonais médios mensais da razão entre arrecadação do setor de cigarros e PIB, ao quadrado - Brasil (2010-2015)

$(\mathrm{Em} \%)$

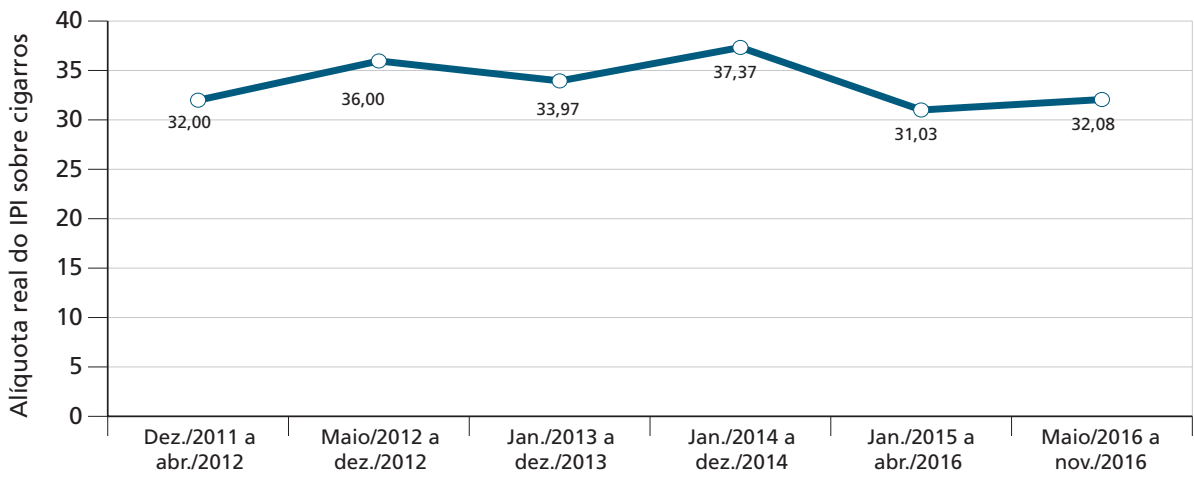

Fontes: Dados básicos da RFB, do Idesf e do Ipeadata.

Elaboração dos autores.

Obs.: Índices sazonais referentes ao período de 2010 a 2015. Períodos que ocorreram alterações nas alíquotas ad valorem e fixa. 
Após a remoção da sazonalidade de cada série, o próximo passo consiste em determinar a ordem de integração de cada variável, via teste de raiz unitária ADF. Porém, antes de se efetuar o teste $\mathrm{ADF}$, é necessário determinar o número de defasagens para cada teste, com o objetivo de garantir que os resíduos não apresentem autocorrelação. Para tal tarefa, foi utilizado o AICC - equação (7). Portanto, para as três variáveis em nível, o critério AICC indicou a necessidade de somente uma defasagem.

Os resultados dos testes de raiz unitária para as três variáveis em nível mostram que as hipóteses nulas de raiz unitária podem ser rejeitadas para as estatísticas $\tau_{\tau} \mathrm{e}$, respectivamente. Porém, para a estatística $\tau$, a probabilidade de se cometer o erro tipo 1 , ou seja, rejeitar a hipótese nula e ela ser verdadeira é elevada, sendo igual a $35,84 \%$, para a variável arrecadação população dessazonalizada; $35,17 \%$, para arrecadação PIB dessazonalizada; e 14,12\%, para arrecadação PIB ao quadrado dessazonalizada (tabela 1). É de amplo conhecimento na literatura econométrica que o teste $\mathrm{ADF}$ tem baixo poder, isto é, seus resultados são muito influenciados pela inserção e/ou remoção de termos determinísticos (constante e tendência). Assim, apesar de dois testes indicarem que a série em nível é estacionária, contra somente um teste que aponta para a presença de raiz unitária, o teste foi realizado novamente, desta vez, com as séries diferenciadas.

TABELA 1

Resultados dos testes de raiz unitária $A D F$, variáveis em nível, relação arrecadação população dessazonalizada, arrecadação PIB dessazonalizada e arrecadação PIB ao quadrado dessazonalizada - Brasil ${ }^{1}$

\begin{tabular}{lccc}
\hline Variáveis & Estatística & Tau calculado & $\operatorname{Pr}<$ Tau \\
\hline ARRECADACAOPOP_SA & $\tau$ & -0.82 & 0.3584 \\
& $\tau_{\mu}$ & -5.69 & 0.0001 \\
ARRECADACAOPIB_SA & $\tau_{\tau}$ & -5.66 & $<.0001$ \\
& $\tau$ & -0.83 & 0.3517 \\
ARRECADACAOPIB2_SA & $\tau_{\mu}$ & -5.54 & 0.0001 \\
& $\tau_{\tau}$ & -5.59 & 0.0001 \\
& $\tau$ & -1.43 & 0.1412 \\
& $\tau_{\mu}$ & -5.18 & 0.0001 \\
\hline
\end{tabular}

Fontes: Dados básicos da RFB, do IBGE, do Idesf, do Ipeadata e da Seade.

Elaboração dos autores.

Nota: ${ }^{1}$ Resultados referentes ao período de janeiro de 2010 até dezembro de 2015.

Obs.: $\tau_{\tau}$ modelo com tendência e constante; $\tau_{\mu}$ : modelo com constante; e $\tau$ : modelo sem tendência e sem constante. 
Novamente, antes da realização dos testes de raiz unitária, foi necessário determinar o número de defasagens nos testes de raiz unitária, desta vez, com as variáveis diferenciadas. O critério AICC indicou doze defasagens.

Conforme apresentado na tabela 2, para todas as variáveis e para todos os modelos, as respectivas hipóteses nulas de raiz unitária podem ser rejeitadas. Portanto, nas diferenças, as três variáveis são estacionárias, ou seja, são integradas de ordem um, pois foi necessário a aplicação de diferença de ordem 1 para que cada uma delas apresentasse um comportamento estacionário

TABELA 2

Resultados dos testes de raiz unitária ADF, variáveis diferenciadas em nível, relação arrecadação população dessazonalizada, arrecadação/faturamento dessazonalizada e arrecadação/faturamento ao quadrado dessazonalizada - Brasil ${ }^{1}$

\begin{tabular}{lccc}
\hline Variáveis & Estatística & Tau calculado & $\operatorname{Pr}<\mathrm{Tau}$ \\
\hline \multirow{2}{*}{ ARRECADACAOPOP_SA } & $\tau$ & -9.89 & $<.0001$ \\
& $\tau_{\mu}$ & -9.82 & 0.0001 \\
& $\tau_{\tau}$ & -9.74 & $<.0001$ \\
ARRECADACAOPIB_SA & $\tau$ & -9.48 & $<.0001$ \\
& $\tau_{\mu}$ & -9.41 & 0.0001 \\
& $\tau_{\tau}$ & -9.35 & $<.0001$ \\
ARRECADACAOPIB2_SA & $\tau$ & -9.13 & $<.0001$ \\
& $\tau_{\mu}$ & -9.06 & 0.0001 \\
& $\tau_{\tau}$ & -9.01 & $<.0001$ \\
\hline
\end{tabular}

Fontes: Dados básicos da RFB, do IBGE, do Idesf, do Ipeadata e da Seade.

Elaboração dos autores.

Nota: ${ }^{1}$ Resultados referentes ao período de janeiro de 2010 até dezembro de 2015.

Obs.: Modelo com tendência e constante; modelo com constante; e modelo sem tendência e sem constante.

Dado que todas as séries são integradas de mesma ordem, então, o próximo passo consiste na realização do teste de cointegração de Engle-Granger. Porém, antes deste teste, é necessário estimar uma regressão com todas as variáveis em nível. Além disso, é necessário realçar que foi necessário aplicar o logaritmo sobre a variável arrecadação sobre populaçáo (log-linear).

Os resultados mostram que todos os parâmetros estimados são estatisticamente significativos para o nível de $1 \%$, conforme resumido na tabela 3. No entanto, para que esses resultados não sejam espúrios, é necessário que as variáveis sejam cointegradas. Conforme o procedimento desenvolvido por Engle e Granger (1991), é necessário capturar os resíduos do modelo de regressão com as variáveis em nível e aplicar o teste de raiz unitária $\mathrm{ADF}$ sobre estes resíduos. Se os resíduos forem estacionários, então, o modelo estimado com as variáveis em nível é denominado de equação de cointegração, ou seja, seus resultados não são espúrios. 
TABELA 3

Equação de cointegração, curva de Laffer - Brasil' ${ }^{1}$

\begin{tabular}{lcccc}
\hline Variável & Estimativa do parâmetro & Erro-padrão da estimativa & Valor do teste $t$ & $p$-value do teste t \\
\hline Intercepto & -0.63959 & 0.06028 & -10.61 & $<.0001$ \\
ARRECADACAOPIB_SA & 0.00184 & 0.00011 & 17.31 & $<.0001$ \\
ARRECADACAO- & -0.00000028 & 0.000000043 & -6.61 & $<.0001$ \\
PIB2_SA & 0.00279 & 0.00039 & 7.16 & $<.0001$ \\
Tendência & & &
\end{tabular}

Fontes: Dados básicos da RFB, IBGE, Idesf, Ipeadata e Seade.

Elaboração dos autores.

Nota: ${ }^{1}$ Resultados referentes ao período de janeiro de 2010 até dezembro de 2015.

Como efetuado anteriormente, antes do teste de raiz unitária, é necessário determinar o número de defasagens. Os resultados do critério AICC indicam somente uma defasagem.

A tabela 4 apresenta os resultados dos testes de raiz unitária sobre os resíduos da regressão com as variáveis em nível para os três modelos. Em todos os testes, as respectivas hipóteses nulas de raiz unitária podem ser rejeitadas no nível de significância de 5\%. Portanto, em nível, os resíduos são estacionários. Isto implica que as variáveis da equação de regressão são cointegradas, ou seja, convergem para o equilíbrio no longo prazo.

TABELA 4

Resultados dos testes de raiz unitária ADF sobre os resíduos da equação de cointegração

\begin{tabular}{lccc}
\hline Variável & Estatística & Tau & $\operatorname{Pr}<$ Tau \\
\hline \multirow{3}{*}{ Resíduos } & $\tau$ & -3.76 & 0.0003 \\
& $\tau_{\mu}$ & -3.74 & 0.0053 \\
& $\tau_{\tau}$ & -3.71 & 0.028 \\
\hline
\end{tabular}

Fontes: Dados básicos da RFB, IBGE, Idesf, Ipeadata e Seade.

Elaboração dos autores.

Obs.: Modelo com tendência e constante; modelo com constante; e modelo sem tendência e sem constante.

Retornando a equação de cointegração, conforme Ventocilla (2011), para encontrar o ponto estacionário da curva de Laffer, igualou-se a equação de regressão a zero e derivou-a em relação à arrecadação sobre o faturamento da indústria de tabaco. Ademais, corroborando com a teoria econômica, destaca-se que o sinal de $\beta_{1}$ é positivo e o sinal de $\beta_{2}$ é negativo.

Logo, ao substituir os valores estimados pelo modelo na equação (11), encontrou-se a alíquota ótima para o IPI da indústria de tabaco no Brasil:

$$
\widehat{A l q}_{I P I}=\frac{-0,00184}{2 *(-0,00000028)} * 100=32,46 \%
$$


esse resultado revela que, com base na teoria da curva de Laffer, a arrecadação por meio do IPI sobre produtos derivados do tabaco, seria máxima se sua alíquota real fosse de $32,46 \%$.

Para comparar a alíquota ótima estimada $\left(\widehat{A l q}_{I P I}\right)$ com a alíquota vigente, analisou-se o Decreto no 7.555 , que dispóe sobre a incidência do IPI sobre cigarros no Brasil (Brasil, 2011). Antes, porém, verificou-se que o Decreto no 8.656 altera os arts. 5 e 7ㅇ para atualizar tanto as alíquotas ad valorem e específicas do IPI sobre cigarros quanto o preço mínimo de venda no varejo (Brasil, 2016). Alteraçóes essas que reforçam o alinhamento das normas relativas ao IPI à política de controle do tabaco proposta no art. 6o da CQCT/OMS.

No Decreto no 8.656, se constatou que, com a alteração do art. 5으, a alíquota nominal ad valorem vigente foi elevada de $0,0 \%$, em dezembro de 2011, para $66,7 \%$, a partir de dezembro de 2016. Da mesma forma, com a alteração do art. 7o, a alíquota específica do IPI aumentou de R \$ 0,80, em dezembro de 2011, para $\mathrm{R} \$ 1,50$, a partir de dezembro de 2016; por maços de cigarro e, para box de cigarro, aumento foi de $\mathrm{R} \$ 1,15$, em dezembro de 2011 , para $\mathrm{R} \$ 1,50$, a partir de dezembro de 2016, para cada unidade.

Conforme se observou no $₫ 1^{\circ}$, do art. 4o․ do Decreto $n^{\circ}$ 7.555, a base de cálculo para a incidência do IPI sobre o cigarro é o valor que resultar da aplicação do valor de 15 pontos percentuais (p.p.) sobre o preço de venda no varejo. Para compreender melhor a norma, utilizou-se o ano de 2015 como referência, o qual exigia que uma alíquota de $60,0 \%$ deveria ser aplicada sobre o montante relativo aos 15 p.p. do preço de venda no varejo, mais uma alíquota fixa de $\mathrm{R} \$ 1,30$ por unidade produzida (tanto para o maço quanto para o box).

Além disso, dividiu-se o montante de IPI arrecadado em 2015 pela quantidade produzida de cigarros entre dezembro de 2014 e novembro de 2015 para encontrar o valor efetivamente pago de IPI, sendo a média de $\mathrm{R} \$ 1,77$ por cigarro produzido. Esse valor serviu de referência para estimar o preço médio de mercado do cigarro para o referido ano, pois, ao simular a regra de apuraçáo do IPI, identificou-se que o preço que resulta no valor efetivamente pago de IPI foi de, aproximadamente, $\mathrm{R} \$ 5,20$. Dessa forma, pôde-se verificar que a base de cálculo foi de $\mathrm{R} \$ 0,78$ (R \$ 5,20 x 15\%); aplicando a alíquota ad valorem de 60\%, obtém-se R \$ 0,47, valor este que deve ser somado a alíquota fixa de $\mathrm{R} \$ 1,30$, o que resulta em $\mathrm{R} \$ 1,77$ por cigarro vendido.

Desse modo, ao dividir o valor efetivamente pago de IPI pelo seu preço de venda estimado, pôde-se verificar que a alíquota real média do IPI, em 2015, foi de $34,07 \%$, próxima à alíquota ótima estimada, de 32,46\%. Aplicando o mesmo procedimento e respeitando a sistemática de tributação do IPI atualizada pelo Decreto no 8.656 , estimou-se a alíquota real para cada período de vigência das 
alíquotas nominais e verificou-se que a alíquota real ficou próxima à alíquota ótima estimada em todos os períodos, conforme apresentado no gráfico 8. Portanto, reduções nas alíquotas nominais para igualá-las à alíquota ótima estimada não provocariam aumentos significativos na arrecadação por meio do IPI.

Conforme ressaltado no início deste trabalho, o primeiro objetivo específico foi estimar a curva de Laffer para o mercado de cigarros levando-se em consideração o IPI. Contudo, diante da realidade brasileira, faz-se necessário avançar na discussão sobre as implicaçóes que isto pode gerar. Assim, como observado, o cigarro é um produto inelástico e, além disso, há um substituto no mercado, qual seja, o cigarro ilegal, a arrecadação com impostos irá declinar tanto no caso de um aumento na alíquota nominal, conforme previsto no art. 5o do Decreto no 8.656 , quanto no caso de implementar a alíquota ótima estimada, visto que a redução do preço, provocada pela nova alíquota, seria mais do que proporcional ao aumento da demanda.

\section{GRÁFICO 8}

Alíquota real do IPI sobre cigarros de acordo com a sistemática de tributação regulamentada pelo Decreto no 7.555, de 19 de agosto de 2011 (dez./2011-nov./2016) (Em \%)

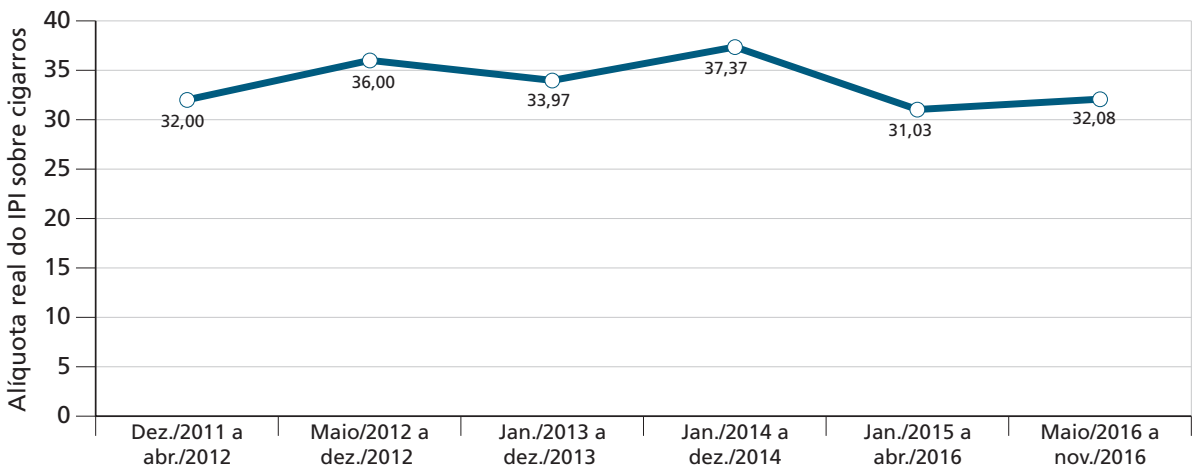

Fonte: Dados básicos da RFB.

Elaboração dos autores.

Obs.: Índices sazonais referentes ao período de 2010 a 2015. Períodos que ocorreram alterações nas alíquotas ad valorem e fixa.

Apesar disso, ao analisar o art. 7ํㅡo do Decreto ํo 8.656 para cumprir o segundo objetivo específico deste trabalho, percebeu-se que o fator que contribuiu para a manutenção da alíquota real do IPI próxima à alíquota ótima estimada foi a política de preço mínimo. A redaçáo dada para o art. $7^{\circ}$ do Decreto no ${ }^{-} .555$, com a instituição do Decreto no 8.656 , estabeleceu que o preço mínimo do cigarro fosse de $\mathrm{R} \$ 3,00$, entre maio de 2012 e dezembro de 2012; de $\mathrm{R} \$ 3,50$, entre janeiro e dezembro de 2013; de $\mathrm{R} \$ 4,00$, entre janeiro e dezembro de 2014; de $\mathrm{R} \$ 4,50$, 
de janeiro de 2015 a abril de 2016; e, a partir de maio de 2016, de R \$ 5,00. Logo, esses aumentos sucessivos no preço mínimo do cigarro diluíram o ônus do IPI sobre o preço de venda no varejo.

Outrossim, os estudos de Carvalho e Lobão (1998) e Iglesias et al. (2007), que estimaram a elasticidade-preço da demanda por cigarros no Brasil e concluíram que a demanda para esse produto tende a ser inelástica de 1983 até 2015, sustentam a assertividade da estratégia de controle do consumo de tabaco adotada pelo Estado brasileiro nas últimas décadas. De fato, de acordo com os dados do gráfico 9, a produção nacional média anual de cigarros reduziu 40,29\% entre 2012 e 2016, enquanto o preço nominal estimado aumentou 148,0\% no mesmo período.

\section{GRÁFICO 9}

Produção e média de preços mensal de cigarros - Brasil (jan./2012-out./2016) (Em milhões de unidades)

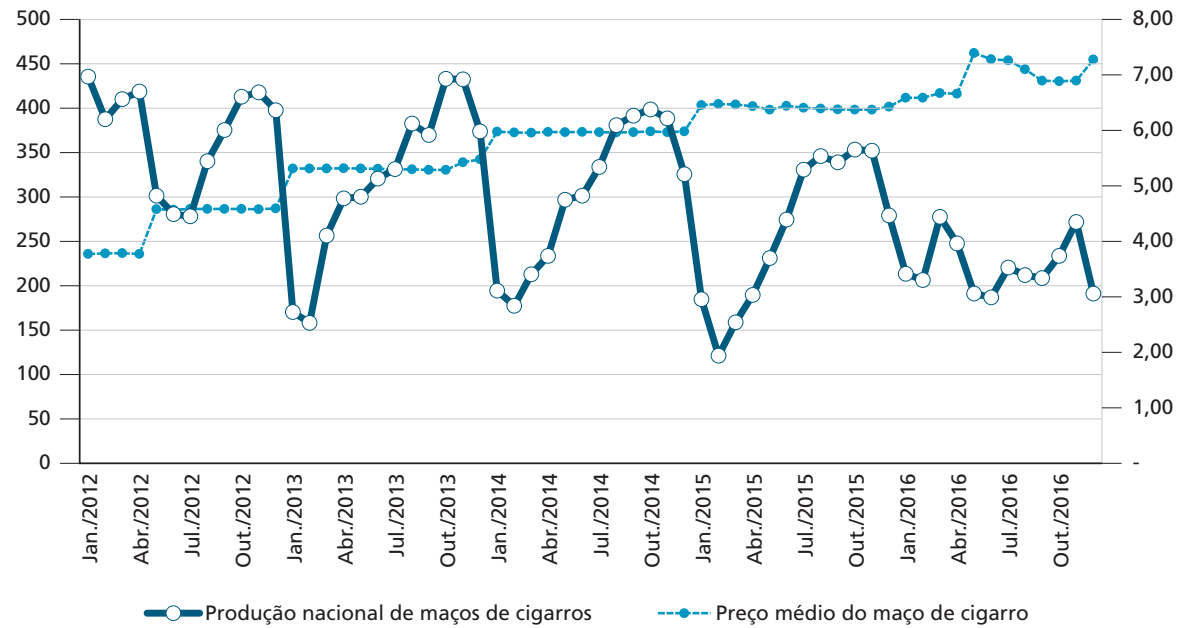

Fontes: Dados básicos da RFB e do Idesf. Elaboração dos autores.

Por sua vez, a média anual de apreensão de cigarros ilegais no país aumentou $232,35 \%$ entre 2012 e 2015, em consonância com os dados do gráfico 10. Apesar dessas apreensóes oscilarem bastante no período, o total apreendido em 2012 correspondeu a 3,78\% da produção nacional, enquanto, em 2015, essas apreensóes corresponderam a $17,70 \%$ da produção nacional. 
GRÁFICO 10

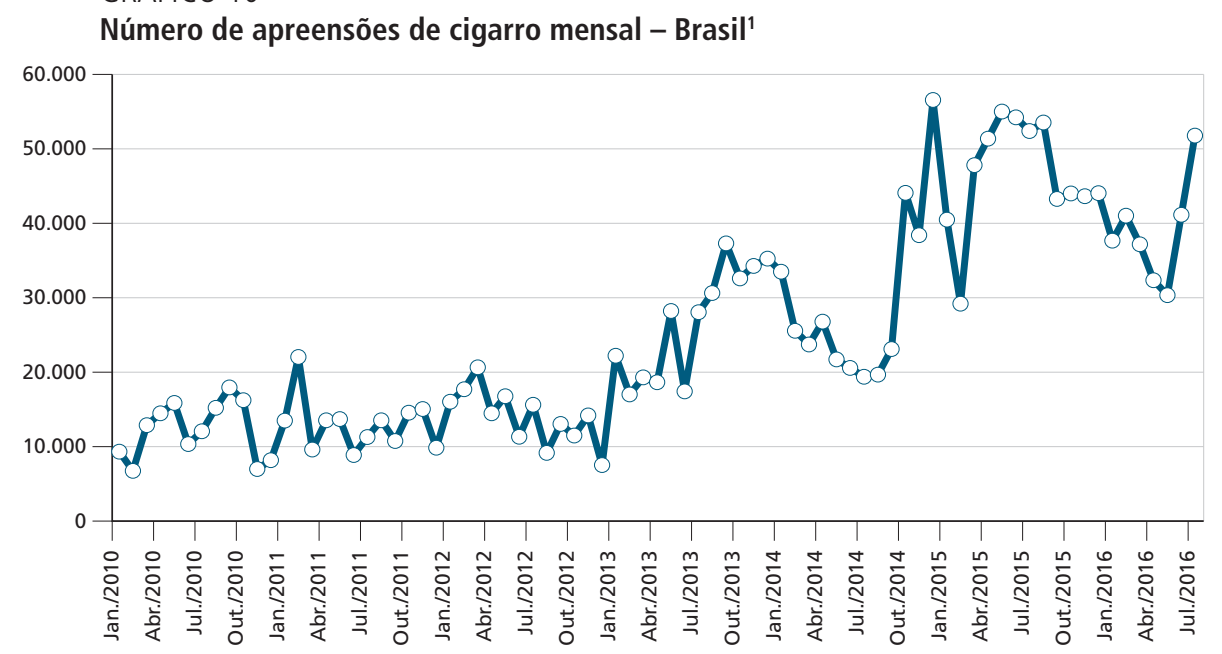

Fontes: Dados básicos da RFB e do Idesf.

Elaboração dos autores.

Nota: ${ }^{1}$ Resultados referentes ao período 2010-2016.

Esses resultados sustentam a evidência de que o cigarro ilegal é um substituto do cigarro legal, pois quando o preço do cigarro legal subiu, o número de apreensões de cigarro também se elevou, o que pode ser considerado uma proxy da demanda por cigarros ilegais. Outra hipótese plausível a partir desses dados é a de que a estratégia de preço mínimo da Política Nacional de Controle do Tabaco (PNCT) está fomentando a indústria de cigarros ilegais no país, visto que o preço de varejo por ela induzido está muito acima do preço dos cigarros ilegais.

Ainda, nessa linha de raciocínio, apesar de significativos os números de apreensôes, as estimativas de Iglesias (2015) mostram que a proporção do mercado ilegal aumentou de $16,6 \%$, em 2008 , para $31,1 \%$, em 2013 , evidência de que os fumantes estão encontrando alternativas à estratégia de controle do tabaco vigente. ${ }^{8}$ Outro resultado relevante desse estudo é que a diferença de preço entre o cigarro lícito e o ilícito aumentou de $-53,0 \%$, em 2008, para -58,4\%, em 2013. Logo, com base nesses resultados, sugere-se uma revisão da política de preço mínimo para cigarros, visto que esse mercado ilegal está retirando receita da indústria legal e reduzindo a receita tributária, que, por consequência, reduz a capacidade do Estado de corrigir as externalidades negativas geradas pelo consumo de tabaco.

Para iniciar essa discussão e atingir o terceiro objetivo específico deste trabalho, simulou-se um cenário, assumindo como verdadeira a hipótese de que a proporção do mercado ilegal continuou em 31,1\% em 2015, dessa forma, ter-se-ia um mercado

8. De acordo com Idesf (2015), 91\% dos cigarros contrabandeados são vendidos em estabelecimentos comerciais formais. 
de 4,653 milhóes de embalagens de cigarro consumidas, 3,206 milhóes advindas do mercado legal e 1,447 milhão do mercado ilegal. Essa hipótese altera apenas o coeficiente linear da curva de demanda por embalagens de cigarros, alteração essa que desloca paralelamente a curva de demanda de $\mathrm{D}_{1}$ para $\mathrm{D}_{2}$, conforme ilustrado no gráfico 11 .

Nessa simulação, assumiu-se também que a diferença de preço entre o cigarro legal e o ilegal permaneceu a mesma em 2013 , ou seja, $58,4 \%$, o que corresponderia a $\mathrm{R} \$ 2,16$ cada embalagem de cigarro ilegal (e não o preço mínimo de $\mathrm{R}$ \$ 4,50, definido no Decreto no 8.656), tendo como referência o valor de $\mathrm{R} \$$ 5,20 do mercado legal, em 2015. Logo, essa hipótese altera apenas o coeficiente angular da curva de oferta por embalagens de cigarro, o que motiva a curva de oferta rotacionar no sentido anti-horário de $\mathrm{O}_{1}$ para $\mathrm{O}_{2}$, conforme ilustrado no gráfico 11 .

Além disso, a possibilidade de oferecer um produto capaz de competir com o produto ilegal implica que o volume de produção dos segmentos low price e ultra low price da indústria nacional também passem a ser comercializados a $\mathrm{R} \$ 2,16$. De acordo com os dados do Idesf, esses dois segmentos representaram, em média, 48\% da produção indústria nacional em 2015, aproximadamente 1,539 milhão de embalagens de cigarro. Logo, somando-se o volume comercializado desses dois segmentos ao volume de embalagens de cigarros ilegais estimados, ter-se-ia um volume de 2,986 milhóes de embalagens de cigarros comercializadas a $\mathrm{R} \$ 2,16$, conforme o ponto (c) do gráfico 11 , o que corresponderia a $64,17 \%$ da produção nacional no novo equilíbrio de mercado.

Dessa forma, para manter a média ponderada pelo share de cada segmento de mercado da indústria nacional igual a $\mathrm{R} \$ 5,20 \mathrm{em} 2015$, verificou-se que o preço médio dos demais segmentos ficou próximo a $\mathrm{R} \$ 10,65$. Em outras palavras, os demais produtos da indústria nacional que constituem os outros $35,83 \%$ no novo equilíbrio de mercado (ou 1,667 milhão de embalagens de cigarros) foram comercializados a $\mathrm{R} \$ 10,65$, preço este que mantém a média ponderada em $\mathrm{R} \$ 5,20$, conforme apresentado no ponto (d) do gráfico 11 .

Portanto, considerando-se as restriçóes listadas nos parágrafos anteriores, a simulação desse cenário partiu da possibilidade de a indústria nacional comercializar embalagens de cigarros no varejo ao preço de $\mathrm{R} \$ 2,16$ para eliminar os cigarros ilegais do mercado. Assim, o resultado da simulação mostra que o equilíbrio de mercado se desloca do ponto (a) para o ponto (b), após a indústria nacional absorver o mercado de cigarro ilegal. Pela ótica da arrecadação do IPI, a absorção do mercado ilegal pela indústria nacional faz com que a área abaixo da curva de Laffer aumente e, no fim da simulação, a área de $\mathrm{L}_{2}$ é maior do que a área de $\mathrm{L}_{1}$ e, o montante arrecadado eleva-se de $\mathrm{R}$ \$ 5,68 bilhôes do ponto (a') para $\mathrm{R} \$ 8,22$ bilhóes no ponto (b'), conforme apresentado no gráfico 11 . 
Apesar disso, conforme ilustrado no gráfico 11, a alíquota real do IPI sobre o volume de embalagens de cigarros comercializados a $\mathrm{R} \$ 2,16$, após a simulação, foi de $69,19 \%$ - ponto (c') -, enquanto a alíquota real do IPI sobre o volume de embalagens comercializadas a $\mathrm{R} \$ 10,65$, foi de $21,21 \%$ - ponto (d').

GRÁFICO 11

Resultado da simulação estática-comparativa sem a política de preço mínimo - Brasil (2015) $11 \mathrm{~A}$ - Equilíbrio de mercado 11B - Curva de Laffer

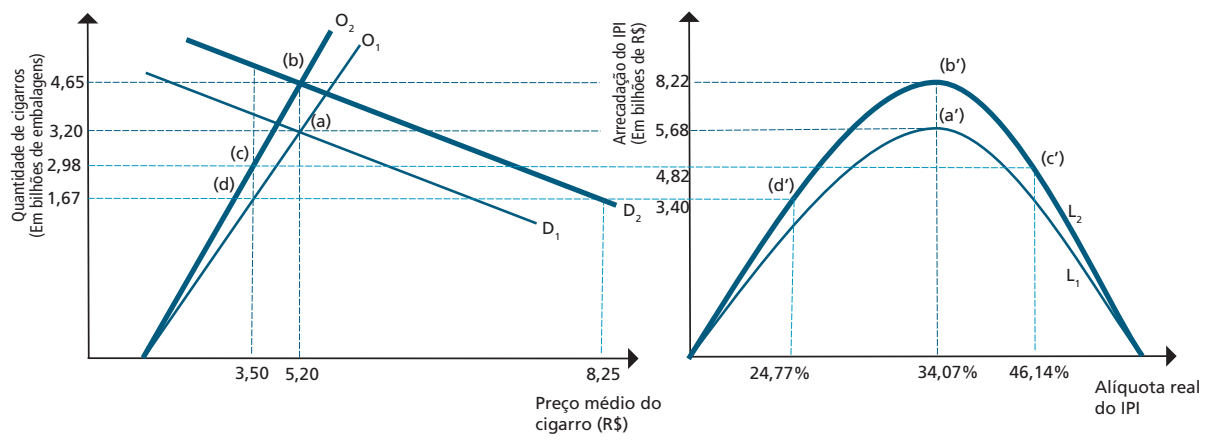

Elaboração dos autores.

Esses resultados da alíquota real do IPI, após a simulação, demonstram que a atual redação do art. 5ํำ do Decreto no 8.656 inviabiliza a indústria nacional de competir com o mercado de cigarros ilegais, pois o percentual correspondente ao IPI no markup para formação do preço do cigarro legal a $\mathrm{R} \$ 2,16$, eleva-se de $34,07 \%$ para $69,19 \%$, ou seja, apenas o IPI arrecadado corresponderia a $69,19 \%$ do preço de comercialização. Por sua vez, a alíquota real do IPI para as demais embalagens de cigarros comercializadas a $\mathrm{R} \$ 10,65$ reduziu de $34,07 \%$ para $21,21 \%$. Em outras palavras, mesmo que não houvesse a restrição de preço mínimo para os cigarros no Brasil, a regra de cálculo do IPI comprometeria a viabilidade de a indústria nacional competir com o mercado de cigarros ilegais e, ainda, a forçaria a elevar o preço para diluir o ônus desse tributo sobre seus produtos.

Nesse sentido, utilizou-se o mesmo modelo para simular qual seria a alíquota fixa ideal para manter o ônus do IPI próximo à alíquota ótima ideal estimada. Para essa simulação, partiu-se da hipótese de que a alíquota fixa do IPI deve ser estratificada de acordo com o segmento de mercado que a embalagem de cigarro atinge. Por exemplo, nos segmentos em que a indústria consegue comercializar embalagens de cigarro mais caras, a alíquota fixa deve ser maior e, nos segmentos em que a indústria precisaria ofertar um produto de baixo valor, a alíquota fixa deve ser menor. Optou-se pela alíquota fixa do IPI como variável de controle para a simulação, pois sua alteração em função da estratificação proposta simplificaria a regra de cálculo do IPI no modelo. 
O resultado dessa simulação indica que, para o ônus do IPI ser equânime entre os diferentes segmentos, a alíquota fixa do IPI sobre as embalagens de cigarro mais baratas (comercializadas a $\mathrm{R} \$ 2,16$ ) deveria ser de $\mathrm{R} \$ 0,54$ por embalagem e não de $R$ \$ 1,30 como determina o Decreto no 8.656 , uma redução de 58,5\%. Por seu turno, a alíquota fixa do IPI sobre as embalagens de cigarros mais caras (comercializadas a $\mathrm{R} \$ 10,65$ ) deveria ser de $\mathrm{R} \$ 2,66$ por embalagem, 104,7\% maior do que a alíquota vigente em 2015. Com essas alíquotas fixas, o ônus total do IPI nas embalagens mais baratas ficaria em torno de $\mathrm{R} \$ 0,73$ por unidade e, nas embalagens mais caras, em torno de $\mathrm{R} \$ 3,62$ por unidade, o que corrobora com uma alíquota real do IPI de 34,07\% para cada estrato da simulação realizada, conforme apresentado no gráfico 12 .

\section{GRÁFICO 12}

Resultado da simulação estática-comparativa sem a política de preço mínimo e com a possibilidade de estratificação da alíquota fixa do IPI - Brasil (2015)

$12 \mathrm{~A}$ - Equilíbrio de mercado 12B - Curva de Laffer

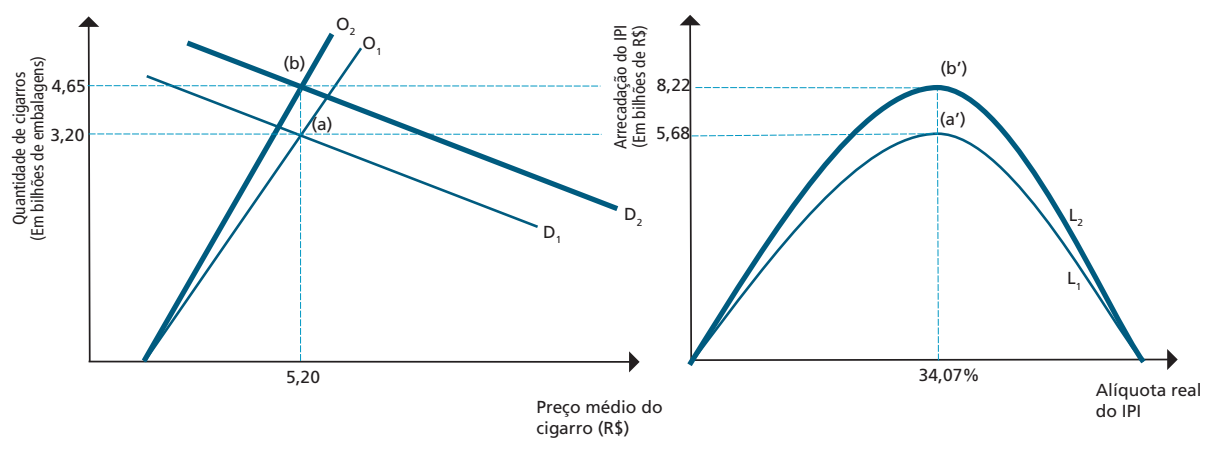

Elaboração dos autores.

A principal diferença nos resultados apresentados nos gráficos 11 e 12 é justamente a regra de cálculo no IPI, sendo que o primeiro evidencia que a regra tributária do IPI inviabiliza a possibilidade de a indústria nacional competir com o mercado ilegal, e o segundo apresenta uma solução plausível para viabilizar a competição da indústria nacional com o mercado ilegal de cigarros.

Os resultados do gráfico 11 mostram que a alíquota real do IPI no equilíbrio de mercado é 34,07\%; no entanto, essa alíquota ocorre em função da média ponderada do valor arrecadado com a mesma regra de cálculo independente do segmento de mercado que a embalagem de cigarro atinge, o que faz o ônus do IPI recair de maneira injusta sobre as embalagens de cigarro que conseguem estratificar o mercado por meio do preço, visto que $45,76 \%$ da arrecadação do IPI adveio das embalagens mais caras e 54,24\% resultou das embalagens mais baratas. Por sua vez, o gráfico 12 demonstra o resultado da possibilidade de ajustar esse 
ônus do IPI de acordo com o markup para a formação do preço para cada segmento de mercado que a embalagem consegue atingir. Nesse sentido, o resultado dessa simulação mostrou que $73,34 \%$ do montante arrecadado por meio do IPI veio dos produtos mais caros, enquanto $26,66 \%$ adveio dos produtos mais baratos.

No fim das simulaçóes, se observou que o faturamento da indústria nacional de cigarros aumentaria de $\mathrm{R} \$ 16,673$ bilhões para $\mathrm{R}$ \$ 24,199 bilhôes, um crescimento de $45,14 \%$, variação que pode ser aproximada pelo valor das áreas dos retângulos dos pontos (a) e (b), respectivamente (gráficos 11 e 12). Cabe ressaltar que os resultados da simulação estática-comparativa levam em consideração a hipótese de que todos os fumantes do mercado ilegal migraram para o mercado legal, o que catalisa o comportamento inelástico da curva de demanda em função do preço. Logo, em função desse aumento da quantidade consumida de cigarros legais, o total de IPI arrecadado aumentou de $\mathrm{R} \$ 5,679$ bilhóes para $\mathrm{R} \$ 8,227$ bilhôes, uma variação de $44,86 \%$, valores que podem ser aproximados pelas áreas abaixo dos pontos (a') e (b’), respectivamente (gráficos 11 e 12).

Dessa forma, caso esse cenário seja plausível para a indústria brasileira, os resultados da simulação mostram um aumento no faturamento da indústria nacional da ordem de $\mathrm{R} \$ 7,526$ bilhóes e, por consequência, um aumento em torno de $\mathrm{R}$ 2,547 bilhóes na arrecadação por meio do IPI, cenário esse que aumentaria a capacidade do Estado em corrigir as externalidades geradas pelo consumo de tabaco e eliminaria o peso do mercado ilegal de tabaco no Brasil.

Por sua vez, poderia se supor que essa redução do preço mínimo, com foco no aumento da demanda por ela induzida, estimularia novos fumantes. Entretanto, levanta-se a hipótese de que esse aumento da demanda refletiria o trade-off dos fumantes de cigarros ilegais para o consumo dos cigarros legais. A evidência para sustentar essa hipótese foi levantada em funçáo dos resultados publicados pela PETab, realizada por IBGE (2008), a qual detectou que $81,4 \%$ dos fumantes não estavam pensando em parar de fumar antes dos próximos doze meses.

$\mathrm{Na}$ PNS de 2013, na seção sobre tabagismo, não houve a mesma pergunta com relação à intenção de parar de fumar, no entanto, a pesquisa mostrou que 17,2\% dos entrevistados declararam ter fumado no passado, mas não indicou a quanto tempo os fumantes deixaram o hábito de fumar, outro dado inconclusivo relativo à expectativa de parar de fumar nessa pesquisa foi de que $51,1 \%$ dos fumantes tentaram parar de fumar, porém não mostrou quantos efetivamente pararam de fumar. Além disso, comparando os dados absolutos de fumantes no Brasil, percebeu-se um aumento no número de fumantes de 21,5 milhóes de fumantes em 2008 para 21,9 milhóes em 2013, com um detalhe a destacar: a PETab de 2008 considerou pessoas de 15 anos de idade ou mais, enquanto a PNS de 2013 considerou pessoas de 18 anos de idade ou mais (IBGE, 2014). 
Nesse sentido, caso essa inferência permanecesse verdadeira para 2015, deduz-se que esse aumento na demanda por cigarros legais ocorreria, em maior peso, devido aos hábitos desses consumidores já fumantes e pelo alívio que essa redução de preços proporcionaria às suas restriçóes orçamentárias e, em menor peso, por novos fumantes. Todavia, cabe ressaltar os resultados de Gardes e Merrigan (2014), que observaram a emersão de uma nova geração de fumantes quando o governo do Canadá decidiu combater o mercado ilegal reduzindo o preço do cigarro no varejo, pois a renda dos jovens é menor e cigarros mais baratos facilitam o seu acesso.

Contudo, a eliminação da política de preço mínimo aumentaria a capacidade de compensação das externalidades negativas provocadas pelo consumo de cigarro pelo Estado. Em outras palavras, o trade-off entre cigarros legais e ilegais induzido por essa redução de preço retiraria recursos do mercado ilegal para o mercado legal, que poderia ser diretamente direcionado para programas que coíbem o hábito de fumar nos mais jovens. Essa dinâmica também teria um impacto indireto na redução dos gastos em saúde, visto que esses consumidores estâo deixando de consumir cigarros de baixa qualidade e passariam a consumir produtos que respeitam as normas exigidas por instituições que regulam esse mercado no país.

Ademais, é plausível deduzir dois outros impactos positivos derivados desse trade-off. O primeiro seria uma possível redução tanto no gasto de recursos de combate direto ao mercado ilegal de cigarros quanto no volume de processos jurídicos e seus consequentes gastos para tratá-los no prazo e modo exigidos em lei. O segundo impacto seria a capacidade de debilitar os agentes envolvidos na produção, distribuição e comercialização de cigarros ilegais, corroborando com o fechamento de estruturas clandestinas ao invés de comprometer a sobrevivência de empresas legalmente constituídas que formam a cadeia produtiva da indústria de tabaco e respeitam as normas ambientais, sanitárias e trabalhistas no país.

\section{CONSIDERAÇÕES FINAIS}

O objetivo deste artigo foi aprofundar o debate sobre a receita tributária gerada a partir da produçáo de produtos derivados do tabaco para compensar suas externalidades negativas, estimando a curva de Laffer para esse mercado, encontrou-se a alíquota real de 32,45\%, que maximizaria a arrecadação tributária do IPI. No entanto, verificou-se que a alíquota real do IPI, entre 2012 e 2015, ficou sempre próxima à alíquota ótima estimada. Desse modo, o foco recaiu sobre a exigência de preço mínimo no varejo para os cigarros no país.

$\mathrm{Na}$ revisão de literatura, verificou-se que o Decreto no 8.656 está alinhado à estratégia proposta no art. $6^{\circ} \mathrm{da}$ FCTC, da OMS, pois ele determinou que a alíquota nominal do IPI, que era de $60,0 \%$ em 2015, mais o valor fixo de $\mathrm{R} \$ 1,30$ por embalagem de cigarro, fosse majorado até que, em maio de 2016, a alíquota 
nominal atingisse $66,7 \%$ e o valor fixo de $\mathrm{R} \$ 1,50$ por maço de cigarro. No entanto, verificou-se nos dados da RFB que, mesmo esse decreto aumentando a alíquota nominal em $11,17 \%$ e o valor fixo do IPI aumentando 15,38\% - entre 2015 e 2016 -, a arrecadação por meio do IPI aumentou $0,49 \%$ e a produção de cigarros caiu $15,55 \%$ no Brasil.

Nessa perspectiva e assumindo como verdadeira a hipótese de que os hábitos dos fumantes no Brasil não se alteraram significativamente entre 2008 e 2015, conforme dados da PETab, realizada por IBGE (2008), e pela PNS, realizada por IBGE (2014), este artigo levanta a hipótese de que essa redução da produção de cigarros no país pode ter sido absorvida, em sua maioria, pelo mercado ilegal de tabaco.

Diante dessas evidências e dos resultados apresentados neste trabalho, questiona-se a eficiência da estratégia de aumentar tributo, para elevar o preço final dos produtos derivados do tabaco e, por consequência, reduzir sua demanda, como política de Estado para o controle do consumo do tabaco e redução de suas externalidades negativas. Infere-se que a insistência nesse vetor de pensamento enfraquece as empresas que operam nas regras estabelecidas pelas instituiçóes democraticamente constituídas e fortalece os agentes que desrespeitam essas regras e operam em sentido contrário à busca por uma sociedade mais justa e equânime.

Este artigo colocou em discussão uma estratégia alternativa para a política de controle do consumo de tabaco no Brasil, visto que seu consumo, há algum tempo, não gera exclusivamente problemas de saúde. Nesse sentido, a revisão da alíquota ótima para o IPI, sobre a ótica da teoria da curva de Laffer, é o primeiro passo para influenciar essa dinâmica entre o mercado legal e o ilegal de tabaco e, ainda, ampliar a capacidade do Estado em fomentar açôes que reduzam o impacto das externalidades negativas criadas pelo consumo de tabaco. Nesse sentido, verificou-se que o cenário ideal, que permitiria a própria indústria nacional do tabaco competir com o mercado ilegal, seria a adoção de uma regra tributária que contemplasse a segmentação de mercado e viabilizasse a produção de embalagens de cigarros a preços próximos aos praticados pelo mercado ilegal.

Conclui-se, portanto, que a estratégia de preço mínimo para o cigarro protege a rentabilidade da indústria de tabaco ilegal e fomenta sua expansão. Verificou-se na simulação de estática-comparativa que a seção dessa estratégia promoveria um robusto ataque na rentabilidade do mercado ilegal de cigarros e transferiria para o Estado brasileiro aproximadamente $\mathrm{R}$ \$ 2,547 bilhóes por meio da arrecadação do IPI e aproximadamente 7,526 bilhôes para a indústria legal nacional. Dado o potencial identificado na alteração da alíquota nominal específica de apenas um imposto, sugere-se também realizar análise semelhante para os demais tributos que incidem sobre os produtos derivados do tabaco, especialmente o imposto sobre 
operaçóes relativas à circulação de mercadorias e sobre prestações de serviços de transporte interestadual, intermunicipal e de comunicação (Imposto sobre Circulação de Mercadorias e Serviços - ICMS) e verificar o real potencial dessa nova abordagem para o Estado.

Além disso, enfatiza-se o risco da emersão de uma nova geração de fumantes provocada pela eliminação da estratégia de preços mínimos, fundamentado pelo estudo de Gardes e Merrigan (2014). Em função desse risco, se recomenda que o aumento da arrecadaçáo estimada seja efetivamente utilizado para programas direcionados à reduçáo das externalidades negativas geradas pelo consumo de tabaco, mais especificamente em programas direcionados às novas geraçóes de adolescentes e jovens adultos, sendo inoportuno o custo de oportunidade gerado pelo uso desses recursos para outras finalidades.

Não obstante, reconhece-se a quantidade de hipóteses e resultados de outras pesquisas para alcançar essa conclusão, ressaltando a necessidade de testar as hipóteses aqui levantadas, bem como atualizar os estudos que contribuíram para esses resultados. Enfatiza-se também a dificuldade de se obter microdados a respeito do tema no Brasil, o que exigirá um esforço institucional e multidisciplinar para avançar a pesquisa sobre este tema no país.

\section{REFERÊNCIAS}

BRASIL. Decreto no 7.555, de 19 de agosto de 2011. Regulamenta os arts. 14 a 20 da Lei no 12.546 , de 14 de dezembro de 2011, que dispóem sobre a incidência do Imposto sobre Produtos Industrializados - IPI, no mercado interno e na importação, relativo aos cigarros classificados no código 2402.20.00 da Tabela de Incidência do Imposto sobre Produtos Industrializados - Tipi, e dá outras providências. Diário Oficial da União, Brasília, 22 ago. 2011. Disponível em: <https://bit.ly/3lhsgMU>. Acesso em: 9 jan. 2017.

. Decreto no 8.656, de 29 de janeiro de 2016. Exclui produtos do regime tributário de que trata o art. $1^{\circ}$ da Lei no 7.798 , de 10 de julho de 1989 , altera a Tabela de Incidência do Imposto sobre Produtos Industrializados - Tipi, aprovada pelo Decreto no 7.660, de 23 de dezembro de 2011, e altera o Decreto no 7.555, de 19 de agosto de 2011. Diário Oficial da Uniáo, Brasília, 29 jan. 2016.

CARVALHO, J.; LOBÃO, W. Vício privado e políticas públicas: a demanda por cigarros no Brasil. Rio de Janeiro: Ipea, 1998.

CHALOUPKA, F. J.; YUREKLI, A.; FONG, G. T. Tobacco taxes as a tobacco control strategy. Tobacco Control, v. 21, p. 172-180, 2012. 
DICKEY, D. A.; FULLER, W. A. Distribution of the estimators for autoregressive time series with unit root. Journal of The American Statistical Association, v. 74, n. 366, p. 427-431, June 1979.

. Likelihood ratio statistics for autoregressive time series with a unit root. Econometrica, v. 49, n. 4, p.1057-1072, July 1981.

ENGLE, R. F.; GRANGER, C. W. J. Long-run economic relationship: readings in cointegration. New York: Oxford University Press, 1991. 301 p. (Advanced texts in econometrics).

FGV - FUNDAÇÃO GETULIO VARGAS. Mosaico orçamentário. Rio de Janeiro: FGV, 2015. Disponível em: <https://bit.ly/3eJH705>. Acesso em: 16 jan. 2017.

FREDO, C. E.; MARGARIDO, M. A. Modelando a sazonalidade e o processo gerador da série de tempo do emprego rural no estado de São Paulo. Revista de Economia e Agronegócio, v. 6, n. 3, p. 367-394, 2008.

FREITAS, S. M.; FERREIRA, C. R. R. P. T.; BARBOSA, M. Z. Oportunidades e entraves à expansão de dendeicultura brasileira. Agricultura em São Paulo, São Paulo, v. 45, abr. 1998, p. 1-16.

GARDES, F.; MERRIGAN, P. Revisiting an important Canadian natural experiment with new methods: an evaluation of the impact of the 1994 tax decrease on smoking. [s.l.]: HALSHS, 2014. Disponível em: <https://bit.ly/3gq6O6N>.

HURVICH, C. F.; TSAI, C. L. Regression and time series model selection in small samples. Biometrika, v. 76, n. 2, 297-307, 1989.

IGLESIAS, R. M. et al. Estimating the size of illicit tobacco consumption in Brazil: findings from the global adult tobacco survey. Tob Control, v. 26, n. 1, p. 53-59, 17 jan. 2017.

IGLESIAS, R. M. et al. Tobacco Control in Brazil. Washington: World Bank, 2007.

IBGE - INSTITUTO BRASILEIRO DE GEOGRAFIA E ESTATÍSTICA. Pesquisa especial de tabagismo. Rio de Janeiro: IBGE, 2008. Disponível em: <https://bit.ly/32uMuLR>. Acesso em: 17 jan. 2017.

Sistema de contas nacionais: nível de atividade de divulgação mais desagregado, referência 2010. Rio de Janeiro: IBGE, 2011.

. Pesquisa Nacional de Saúde 2013: percepção do estado de saúde, estilos de vida e doenças crônicas. Rio de Janeiro: IBGE, 2014. Disponível em: <https://bit.ly/3eJqH7W>. Acesso em: 17 jan. 2017. 
IDESF - INSTITUTO DE DESENVOLVIMENTO ECONÔMICO E SOCIAL DE FRONTEIRAS. Base de dados da pesquisa: o custo do contrabando. Foz do Iguaçu: Idesf, 2015. Disponível em: <https://bit.ly/3pxmFEX>. Acesso em: 25 nov. 2016.

LAFFER, A. The Laffer Curve: past, present, and future. Whasinghton, D.C.: Heritage Foundation, 2004. Disponível em: $<$ https://herit.ag/35frNWe>. Acesso em: 24 jan. 2017.

LEVY, D.; ALMEIDA, L. M.; SZKLO, A. The Brazil SimSmoke Policy Simulation Model: The effect of strong tobacco control policies on smoking prevalence and smoking - attributable deaths in a middle income nation. PLoS Med, v. 9, n. 11, 2012.

MACKINNON, J. G. Critical values for cointegration tests. Ontario: QED, 1991. (Working Paper, n. 1227).

PAES, N. L. Tributação dos cigarros: uma análise abrangente da literatura. Human and Social Sciences, v. 36, n. 2, p. 177-187, 2014.

PHILLIPS, P. C. B; OULIARIS, S. Asymptotic properties of residual based tests for cointegration. Econometrica: Journal of the Econometric Society, p. 165193, 1990.

PINTO, M. T.; PICHON-RIVIERE, A. Carga das doenças tabaco relacionadas para o Brasil. Rio de Janeiro, 2012.

SIMONSEN, M. H.; CYSNE, R. P. Macroeconomia. 3. ed. Rio de Janeiro: Editora Atlas, 2007.

TRABANDT, M.; UHLIG, H. The Laffer curve revisited. Journal of Monetary Economics, v. 58, n. 4, p. 305-327, May 2011.

VARIAN, H. R. Intermediate Microeconomics: a modern approach. New York: W.W. Norton \& Company, 1996. 650 p.

VENTOCILLA, J. E. En busca de la curva de Laffer para el caso peruano. Horizonte económico, v. 1, 2011.

WHO - WORLD HEALTH ORGANIZATION. Framework Convention on Tobacco Control. Geneva: WHO, 2003.

Guidelines for implementation of Article 6: Price and tax measures to reduce the demand for tobacco. Punta del Este: WHO, 2010. (Technical report by WHO's Tobacco Free Initiative). Disponível em: <https://bit.ly/3liNHNK>. Acesso em: 20 dez. 2015. 
YAFFEE, R.; MCGEE, M. Introduction to time series analysis and forecastring with applications of SAS and SPSS. New York: Academic Press, 2000. 528 p.

\section{BIBLIOGRAFIA COMPLEMENTAR}

BRASIL. Decreto no 8.556 , de 6 de junho de 2002. Exclui produtos do regime tributário de que trata o art. $1^{\circ}$ da Lei no 7.798 , de 10 de julho de 1989 , altera a Tabela de Incidência do Imposto sobre Produtos Industrializados - Tipi, aprovada pelo Decreto ํo 7.660, de 23 de dezembro de 2011, e altera o Decreto no 7.555 , de 19 de agosto de 2011. Diário Oficial da União, Brasília, 7 jun. 2002. Seção 1. Disponível em: <https://bit.ly/38oYUsn>. Acesso em: 9 jan. 2017.

. Lei no 12.546 , de 14 de dezembro de 2011. Institui o Regime Especial de Reintegração de Valores Tributários para as Empresas Exportadoras (Reintegra); dispóe sobre a redução do Imposto sobre Produtos Industrializados (IPI) à indústria automotiva; altera a incidência das contribuiçōes previdenciárias devidas pelas empresas que menciona; altera as Leis no 11.774 , de 17 de setembro de 2008, no 11.033, de 21 de dezembro de 2004, no 11.196, de 21 de novembro de 2005, $\mathrm{n}^{\mathrm{o}} 10.865$, de 30 de abril de 2004, no 11.508, de 20 de julho de 2007, no 7.291, de 19 de dezembro de 1984, no 11.491, de 20 de junho de 2007, no 9.782, de 26 de janeiro de 1999, e no 9.294, de 15 de julho de 1996, e a Medida Provisória no 2.199-14, de 24 de agosto de 2001; revoga o art. 1o da Lei no 11.529, de 22 de outubro de 2007, e o art. 6o do Decreto-Lei no 1.593, de 21 de dezembro de 1977, nos termos que especifica; e dá outras providências. Diário Oficial da Uniáo, Brasília, 15 dez. 2011. Disponível em: <https://bit.ly/36iEBKG>. Acesso em: 9 jan. 2017.

. Receita Federal do Brasil. Regimes e controles especiais: cigarros. Disponível em: <http://idg.receita.fazenda.gov.br/orientacao/tributaria/regimes-e-controles-especiais>. Acesso em: 5 jan. 2017.

DAGUM, E. B. The X11ARIMA/88 Seasonal Adjustment Method: Foundations and User's Manual. Ottawa: Time Series Research and Analysis Division; Statistics Canada, p. 1-3. 1998.

DAGUM, E. B.; CHAB, N.; CHIU, K. Derivation and Properties of the X11ARIMA and Census II Linear Filters. Journal of Official Statistics, v. 12, n. 4, Statistics Sweden, p. 329-348, 1996.

IBGE - INSTITUTO BRASILEIRO DE GEOGRAFIA E ESTATÍSTICA. Índice de preços ao consumidor amplo. Disponível em: <https://bit.ly/2GHQcdl>. Acesso em: 21 jan. 2017. 
IPEA - INTITUTO DE PESQUISA ECONÔMICA APLICADA. Indicadores Ipea. Disponível em: <http://www.ipeadata.gov.br>. Acesso em: 24 jan. 2017.

SEADE - FUNDAÇÃO SISTEMA ESTADUAL DE ANÁLISE DE DADOS. Informaçáo dos municípios paulistas. Disponível em: <https://bit.ly/38pnJ7x>. Acesso em: 24 jan. 2017.

Data da submissão: 9/6/2018

Primeira decisão editorial em: 3/8/2018

Última versão recebida em: 8/1/2019

Aprovação final em: 21/1/2019 


\section{Ipea - Instituto de Pesquisa Econômica Aplicada}

\section{EDITORIAL}

\section{Chefe do Editorial}

Reginaldo da Silva Domingos

\section{Assistentes da Chefia}

Rafael Augusto Ferreira Cardoso

Samuel Elias de Souza

\section{Supervisão}

Camilla de Miranda Mariath Gomes

Everson da Silva Moura

\section{Revisão}

Amanda Ramos Marques

Ana Clara Escórcio Xavier

Clícia Silveira Rodrigues

Idalina Barbara de Castro

Luiz Gustavo Campos de Araújo Souza

Olavo Mesquita de Carvalho

Regina Marta de Aguiar

Hellen Pereira de Oliveira Fonseca (estagiária)

Ingrid Verena Sampaio Cerqueira Sodré (estagiária)

\section{Editoração}

Aeromilson Trajano de Mesquita

Cristiano Ferreira de Araújo

Danilo Leite de Macedo Tavares

Herllyson da Silva Souza

Jeovah Herculano Szervinsk Junior

Leonardo Hideki Higa

\section{Capa}

Luís Cláudio Cardoso da Silva

\section{Projeto Gráfico}

Renato Rodrigues Bueno

The manuscripts in languages other than Portuguese published herein have not been proofread.

\section{Livraria Ipea}

SBS - Quadra 1 - Bloco J - Ed. BNDES, Térreo

70076-900 - Brasília - DF

Tel.: (61) 2026-5336

Correio eletrônico: livraria@ipea.gov.br 

Composto em adobe garamond pro 11/13,2 (texto) Frutiger 67 bold condensed (títulos, gráficos e tabelas) Brasília-DF 